NBER WORKING PAPER SERIES

\title{
SECTORAL VS. AGGREGATE SHOCKS: \\ A STRUCTURAL FACTOR ANALYSIS OF INDUSTRIAL PRODUCTION
}

\author{
Andrew T. Foerster \\ Pierre-Daniel G. Sarte \\ Mark W. Watson \\ Working Paper 14389 \\ http://www.nber.org/papers/w14389 \\ NATIONAL BUREAU OF ECONOMIC RESEARCH \\ 1050 Massachusetts Avenue \\ Cambridge, MA 02138 \\ October 2008
}

The views expressed in this paper are those of the authors and do not necessarily reflect those of the Federal Reserve Bank of Richmond or the Federal Reserve System. We thank Andreas Hornstein, Ray Owens, and Roy Webb for helpful conversations. Support was provided by the National Science Foundation through grant SES-0617811. Data and replication files for this research can be found at http://www.princeton.edu/ mwatson. The views expressed herein are those of the author(s) and do not necessarily reflect the views of the National Bureau of Economic Research.

NBER working papers are circulated for discussion and comment purposes. They have not been peerreviewed or been subject to the review by the NBER Board of Directors that accompanies official NBER publications.

(C) 2008 by Andrew T. Foerster, Pierre-Daniel G. Sarte, and Mark W. Watson. All rights reserved. Short sections of text, not to exceed two paragraphs, may be quoted without explicit permission provided that full credit, including $(\odot$ notice, is given to the source. 
Sectoral vs. Aggregate Shocks: A Structural Factor Analysis of Industrial Production

Andrew T. Foerster, Pierre-Daniel G. Sarte, and Mark W. Watson

NBER Working Paper No. 14389

October 2008

JEL No. C32,E23,E32

\begin{abstract}
$\underline{\text { ABSTRACT }}$
This paper uses factor analytic methods to decompose industrial production (IP) into components arising from aggregate shocks and idiosyncratic sector-specific shocks. An approximate factor model finds that nearly all $(90 \%)$ of the variability of quarterly growth rates in IP are associated with common factors. Because common factors may reflect sectoral shocks that have propagated by way of input-output linkages, we then use a multisector growth model to adjust for the effects of these linkages. In particular, we show that neoclassical multisector models, of the type first introduced by Long and Plosser (1983), produce an approximate factor model as a reduced form. A structural factor analysis then indicates that aggregate shocks continue to be the dominant source of variation in IP, but the importance of sectoral shocks more than doubles after the Great Moderation (to 30\%). The increase in the relative importance of these shocks follows from a fall in the contribution of aggregate shocks to IP movements after 1984.
\end{abstract}

Andrew T. Foerster

Department of Economics

Duke University

Durham, NC 27708

andrew.foerster@duke.edu

Pierre-Daniel G. Sarte

Research Department.

Federal Reserve Bank of Richmond

PO Box 27622

Richmond, VA 23261

pierre.sarte@rich.frb.org
Mark W. Watson

Department of Economics

Princeton University

Princeton, NJ 08544-1013

and NBER

mwatson@princeton.edu 


\section{Introduction}

The Federal Reserve Board's Index of Industrial Production (IP) is an important indicator of aggregate economy activity in the United States. Month-to-month and quarter-to-quarter variations in the index are large. Monthly and quarterly growth rates for the seasonally adjusted IP index over 1972-2007 are plotted in Figure 1. Over this sample period, the standard deviation of monthly growth rates was over eight percentage points (at an annual rate), and quarterly growth rates had a standard deviation of nearly six percentage points. Also evident in the figure is the large fall in volatility associated with the Great Moderation; the standard deviation in the post- 84 period is roughly half its pre- 84 value for both the monthly and quarterly series.

Because the IP index is constructed as a weighted average of production indices for a large number of sectors, the large volatility in the IP index is somewhat puzzling. Simply put, while production in an individual sector (e.g. "Motor Vehicle Parts") may vary substantially from month-to-month or quarter-to-quarter, apparently much of this variability does not "average out" in the index of economy-wide production. There are three leading explanations for this observation. The first relies on aggregate shocks that affect all industrial sectors. Since these shocks are common across sectors, they do not average out and become the dominant source of variation in aggregate economic activity. The two other explanations rely on uncorrelated sector-specific shocks. First, Gabaix (2005) notes that sector-specific shocks may not necessarily average out when some of these sectors have large weights in the aggregate index. Second, complementarities in production such as input-output linkages may propagate sector-specific shocks throughout the economy in a way that generates substantial aggregate variability.

The literature analyzing sector-specific versus aggregate sources of variations in the business cycle has followed two main approaches. Long and Plosser (1987), Forni and Reichlin (1998), and Shea (2002) among others rely on factor analytic methods, coupled with broad identifying restrictions, to assess the relative contributions of aggregate and sector-specific shocks to aggregate variability. These papers generally find that sector-specific shocks contribute a non-trivial fraction of aggregate fluctuations (e.g. approximately 50 percent in Long and Plosser (1987)). A second strand of literature is rooted in more structural calibrated multisector models, such as Long and Plosser (1983) or Horvath (1998, 2000), that explicitly take into account input-output linkages across sectors. In these models, whether input-output linkages are sufficiently strong to generate substantial aggregate variability 
from sector-specific shocks depends on the exact structure of the input-output matrix. ${ }^{1}$

This paper bridges these two approaches and sorts through the leading explanations underlying both the volatility of IP and its decline in the post-1984 period. In particular, it describes conditions under which neoclassical multisector models that explicitly consider input-output linkages, such as those of Long and Plosser (1983) or Horvath (1998), produce an approximate factor model as a reduced form. Aggregate shocks to sectoral productivity emerge as the common output factors in the approximate factor model. The "uniquenesses" in the factor model are associated with sector-specific shocks. However, because input-output linkages induce some correlation across the "uniquenesses", the estimated factors may be biased and reflect not only aggregate shocks but also idiosyncratic shocks that propagate across sectors by way of these input-output linkages.

Ultimately, our analysis suggests that sectoral weights play little role in explaining the variability of the aggregate IP index. As in Shea (2002), aggregate variability is driven mainly by covariability across sectors and not sector-specific variability. In addition, consistent with Quah and Sargent (1993), who study comovement in employment across 60 industries, and Forni and Reichlin (1998), who study annual U.S. output and productivity data over 19581986, we find that much of the covariability in sectoral production can be explained by a small number of common factors. These common factors are the leading source of variation in the IP index, and a decrease in the variability of these common factors drives the post-1984 decline in aggregate volatility.

Because common factors may reflect not only aggregate shocks but also the propagation of sectoral shocks by way of input-output linkages, we draw on a generalized version of the multisector growth model introduced in Horvath (1998) to filter out the effects of those linkages. Using input-output matrices calibrated to the U.S. production sector, we find that sectoral shocks generally play a modest role in the variability of aggregate IP. That said, the relative importance of these shocks more than doubles in the post-1984 period. Specifically, while sectoral shocks account for roughly 12 percent of the volatility of aggregate IP prior to 1984, they account for about 30 percent of IP fluctuations after the onset of the Great Moderation. Moreover, our analysis suggests that changes in the structure of the U.S. inputoutput matrix have not lead to greater propagation of sector-specific shocks in the post-1984 period. Rather, given that the magnitude of sectoral shocks is roughly unchanged before and after 1984, the increase in the relative importance of these shocks follows from a decrease in the contribution of aggregate shocks to the variability of aggregate IP.

\footnotetext{
${ }^{1}$ See Dupor (1999), and more generally Carvalho (2007).
} 
This paper is organized as follows. Section 2 introduces the sectoral data, and studies the role of sectoral weights and sector-specific variation in explaining the variability of the aggregate IP index. Section 3 asks whether the covariability across sectors can be explained by a small number of common factors, and quantifies the role that these common shocks play in the variability of the IP index. In section 4, we show that a generalized version of the multisector growth model introduced by Horvath (1998) admits an approximate factor model as a reduced form. We then calibrate the model using input-output matrices for the U.S. production sector to construct a model-based filter that eliminates the effects of inputoutput linkages. This allows us to isolate the effects of aggregate productivity shocks from the common factors estimated in section 3. Section 5 offers concluding remarks.

\section{A First Look at the Sectoral Data}

\subsection{Overview of the Data}

The analysis uses data on Industrial Production over the period 1972-2007 obtained from the Board of Governors, and Benchmark Input-Output tables provided by the Bureau of Economic Analysis (BEA). Benchmark input-output tables are available only every five years, but provide a greater level of disaggregation relative to tables that are available in non-benchmark years. For most of the paper, IP data is disaggregated by sectors according to the North American Industry Classification System (NAICS). The raw data are indices of real output, from which we compute sectoral growth rates as well as the relative importance (or shares) of industries in aggregate IP. The "Use Table" measures the value of inputs in producer prices, given by commodity codes, used by each industry, given by industry codes, as well as payments to labor and capital. To account for possible low frequency changes in the structure of input-output linkages across sectors, we consider two benchmark years, 1977 and 1997. Because NAICS definitions are relatively recent and cannot be matched to input-output tables prior to 1997, we also make use of vintage IP data covering the period 1967-2002. The vintage IP data are disaggregated according to Standard Industry Classification (SIC) codes, and discontinued after 2002. A detailed description of the data is provided in Appendix A, and their main properties are described in Table A1.

Let $I P_{t}$ denote the value of the aggregate IP index at date $t$, and $I P_{i t}$ the index for the $i^{\prime}$ th sector. These indices are available monthly. Quarterly values of the indices are constructed as averages of the months in the quarter. Growth rates (in percentage points) are denoted by $g_{t}$ for aggregate IP and $x_{i t}$ for sectoral IP. We compute $g_{t}$ as $1200 \times \ln \left(I P_{t} / I P_{t-1}\right)$ and 
$400 \times \ln \left(I P_{t} / I P_{t-1}\right)$ for monthly and quarterly frequencies respectively, and compute $x_{i t}$ similarly.

\subsection{Sectoral Summary statistics}

Figure 2 shows the distributions of standard deviations of both monthly and quarterly sectoral growth rates over the sample periods 1972-1983 and 1984-2007. In computing these distributions, IP is broken down into 117 sectors that correspond roughly to a four digit level of disaggregation. Monthly growth rates are volatile and fell only slightly during the second period (the median standard deviation fell from 30 percent in the first period to 25 percent in the second period). Quarterly averaging reduces the volatility of sectoral output growth, and a fall in the volatility of sectoral quarterly growth rates is evident after 1984 . Table 1 summarizes the contemporaneous cross-correlation of the sectoral growth rates. Average pairwise correlations are positive, lower for the monthly data than the quarterly data, and lower in the second sample period than in the first. Looking at the extremes in the table, quarterly growth rates were relatively highly correlated in the first period (the average correlation was 0.27 over 1972-1983), while monthly growth rates were relatively weakly correlated over the second period (the average correlation was 0.05 over 1984-2007).

Let $w_{i t}$ denote the share (or weight) of sector's $i$ production in the aggregate index. Growth in aggregate IP can then be written as $g_{t}=\sum_{i} w_{i t} x_{i t}$. Table 2 follows Shea (2002) and studies two sources of variation in the aggregate IP index: (i) time variation in the sectoral shares, $w_{i t}$, used as weights in combining sectoral growth rates to produce aggregate growth rates, and (ii) the covariance of sectoral growth rates.

Panel (a) of Table 2 shows the standard deviation of $g_{t}$, the standard deviation of $\sum_{i} \bar{w}_{i} x_{i t}$, where $\overline{w_{i}}$ denotes the sample average of $w_{i t}$ over the sample period, and the standard deviation of $N^{-1} \sum_{i} x_{i t}$, where $N$ is the number of sectors. It is apparent that the standard deviations of $g_{t}$ and $\sum_{i} \bar{w}_{i} x_{i t}$ are nearly identical, indicating that time variation in $w_{i t}$ is not an important source of variability in aggregate IP. Moreover, these values are close to the standard deviation of IP computed using equal share weights, so that the distribution of shares across sectors is relatively unimportant in this calculation as well. Moreover, because the variability when using equal weights is somewhat larger than when using $\overline{w_{i}}$, larger sectors have less volatile output growth rates than smaller sectors on average.

Panel (b) considers estimates of the standard deviation of $g_{t}$ that ignore the covariance of sectoral growth rates. Letting $\widehat{\sigma}_{i}^{2}$ denote the sample variance in $x_{i t}$, the first entry in panel (b) shows $\left[\sum_{i} \widehat{\sigma}_{i}^{2}\left(T^{-1} \sum_{t} w_{i t}^{2}\right)\right]^{1 / 2}$, the second entry shows $\left[\sum_{i} \widehat{\sigma}_{i}^{2}{\overline{w_{i}}}^{2}\right]^{1 / 2}$, and the last entry shows 
$\left[\sum_{i} \widehat{\sigma}_{i}^{2} N^{-2}\right]^{1 / 2}$. Again all values are similar, suggesting that neither time variation in $w_{i t}$ nor distributional concerns are important in these calculations. More importantly, the entries in panel (b) are markedly smaller than those in panel (a). Evidently, as stressed by Shea (2002), most of the variance in aggregate output growth is associated with the covariance of sectoral growth rates. If one were to assume that the comovement in sectoral growth rates is driven by aggregate shocks that are common to all sectors, it would immediately follow from Table 2 that these shocks represent the overriding source of variation in aggregate IP. For example, using quarterly growth rates and constant mean shares over the sample period 1984-2007, the fraction of IP growth variability explained by aggregate shocks would be approximately

$1-(1.5 / 3.6)^{2}$ or 0.83 . Note, however, that this calculation is only approximate since the diagonal elements of the covariance matrix used in panel (b) would themselves reflect, in part, the effects of aggregate shocks. Finally, panels (a) and (b) of Table 2 suggests that the fall in the volatility of aggregate IP in the post-1984 period is associated mainly with a fall in the covariability of sectoral growth rates rather than a decline in the variability of output growth in individual sectors.

To sum up, the results in Table 2 allow us to discount the "large shocks in sectors with large shares" explanation for the variability of aggregate output. If anything, we find that on average, larger sectors are associated with lower output growth volatility. In addition, the variability in aggregate IP is associated with shocks that lead to covariability in sectoral output, not shocks that lead to large idiosyncratic sectoral variability. The remaining challenge is to measure and understand the shocks that lead to covariability, and this challenge is taken up in the next two sections. Throughout the remainder of the paper, the analysis is carried out using constant mean shares, $\overline{w_{i}}$.

\section{Statistical Factor Analysis}

As discussed in Forni and Reichlin (1998), the approximate factor model is one natural way to model the covariance matrix of sectoral production. Letting $X_{t}$ represent the $N \times 1$ vector of sectoral growth rates, this model represents $X_{t}$ as

$$
X_{t}=\Lambda F_{t}+u_{t}
$$

where $F_{t}$ is a $k \times 1$ vector of latent factors, $\Lambda$ is an $N \times k$ matrix of coefficients called factor loadings, and $u_{t}$ is an $N \times 1$ vector of sector-specific idiosyncratic disturbances. We denote the number of time series observations by $T$. In classical factor analysis (Anderson 
(1984)), $F_{t}$ and $u_{t}$ are mutually uncorrelated i.i.d. sequences of random variables, and $u_{t}$ has a diagonal covariance matrix. Thus, $X_{t}$ is an i.i.d. sequence of random variables with covariance matrix $\Sigma_{X X}=\Lambda \Sigma_{F F} \Lambda^{\prime}+\Sigma_{u u}$, where $\Sigma_{F F}$ and $\Sigma_{u u}$ are the covariance matrices of $F_{t}$ and $u_{t}$ respectively. Because $\Sigma_{u u}$ is diagonal, any covariance between the elements of $X_{t}$ arises from the common factors $F_{t}$.

Approximate factor models (e.g. Chamberlain and Rothschild (1983), Connor and Korackzyk (1986), Forni, Halli, Lippi, and Reichlin (2000), and Stock and Watson (2000)), weaken these assumptions by (essentially) requiring that key sample moments involving $F_{t}$ and $u_{t}$ mimic the behavior of sample moments in classical factor analysis. This allows for weak cross sectional and temporal dependence in the series, subject to the constraint that sample averages satisfy laws of large numbers with the same limits as those that would obtain in classical factor analysis. When $N$ and $T$ are large, as they are in this paper's application, the approximate factor model has proved useful because relatively simple methods can be used for estimation and inference. For example, penalized least squares criteria can be used to consistently estimate the number of factors (Bai and $\mathrm{Ng}$ (2002)), principal components can be used to consistently estimate factors (Stock and Watson (2000)), and the estimation error in the estimated factors is sufficiently small that it can be ignored when estimating variance decompositions or conducting inference about $\Lambda$ (Stock and Watson (2000), Bai (2003)).

Tables 3 through 5, as well as Figures 3 and 4, summarize the results from applying these methods to the data on sectoral IP growth rates. To begin, we estimated the number of factors using the Bai and Ng (2002) ICP1 and ICP2 estimators. These estimators yielded 2 factors in the full sample period (1972-2007), and first sample period (1972-1983). They yielded 1 factor in the second sample period (1984-2007) $)^{2}$. The findings shown in Tables 3 through 5 and Figures 3 and 4 are based on estimated 2-factor models. For robustness, we also carried out our analysis using 1- and 3-factor models. The results (not shown) were similar to those we report for the 2-factor model.

Given equation (1), we can gauge the importance of common shocks, $F_{t}$, relative to the "uniquenesses," $u_{t}$, in two ways. First, we compute the fraction of aggregate IP variability explained by common shocks, which we denote by $R^{2}(F)$. In particular, letting $\mathbf{w}$ denote the $N \times 1$ vector of constant mean shares, $g_{t}=\mathbf{w}^{\prime} \Lambda F_{t}+\mathbf{w}^{\prime} u_{t}$ so that $R^{2}(F)=\mathbf{w}^{\prime} \Lambda \Sigma_{F F} \Lambda^{\prime} \mathbf{w} / \sigma_{g}^{2}$, where $\sigma_{g}^{2}$ is the variance of IP growth rates. Second, we can also assess the extent to which

\footnotetext{
${ }^{2}$ The estimators are based on the eigenvalues of the sample correlation matrix of the data. These are presented and discussed in Section 4.
} 
the common factors explain output growth variability in individual sectors. That is, we can also compute the distribution of $R^{2}$ statistics obtained by regressing $x_{i t}$ on $F_{t}$, which we denote by $R_{i}^{2}(F)$.

Table 3 shows the 2-factor model's implied standard deviation of aggregate IP computed using constant shares, as well as the fraction of aggregate IP variability explained by the common factors, $R^{2}(F)$. The factor model implies an aggregate IP index with volatility that is essentially identical to that found in the data. Furthermore, the common factors explain nearly all of the variability in quarterly growth rates of the aggregate IP index over both sample periods. Common shocks also explain the bulk of the variability in monthly growth rates over the 1972-1983 period, but only half of the variance of monthly growth rates over the 1984-2007 period. Figure 3 illustrates aggregate IP growth rates as well as the model's fitted values of the factor component. Consistent with the variance decomposition in Table 3 , the series track one another closely for the quarterly data. The series also track each other closely for the monthly data in the early sample period, but less so over the period 19842007. While the factor component tracks low-frequency movements in monthly growth rates relatively well over this second period, several of the high frequency spikes in the monthly series are associated with sector-specific shocks.

Because the common factors explain roughly 90 percent of the variability in quarterly growth rates over both sample periods, they are responsible for 90 percent of the decrease in aggregate volatility across the two time periods. Similarly, common shocks explain 85 and 50 percent of the variability in monthly growth rates over 1972-1983 and 1984-2007 respectively, and a decrease in the magnitude of these shocks fully explains the decrease in variability of the monthly series after 1984. Taken together, these findings suggest that the Great Moderation is explained by a decrease in the variance of the common components of IP.

At a more disaggregated level, Figure 4 shows the fraction of output growth variability in individual IP sectors explained by the common factors. Regarding individual monthly sectoral growth rates, these factors account for only a small fraction of their variability both before and after 1984. (the median value is 18 percent in the 1972-1983 period and 10 percent in the 1984-2007 period). In contrast, common shocks play a non-trivial role in driving the movements of sectoral quarterly growth rates prior to 1984. Specifically, over the first sample period, common factors explain at least 41 percent of output growth volatility in half of the sectors, and are the main source of variability in 25 percent of the sectors. Interestingly, the relative importance of common shocks for the variability of sectoral quarterly growth rates 
falls considerably after the onset of the great moderation. After 1984, the median $R_{i}^{2}(F)$ statistic is only 19 percent, so that idiosyncratic shocks take on a more prominent role at the sectoral level over the second sample period.

Surprisingly, while the importance of common shocks for the variability of sectoral quarterly growth rates declines after 1984, observe in Figure 4 that these shocks nevertheless explain a very large fraction of output growth volatility in several individual series in both sample periods. Table 4 lists the ten sectors with the largest fraction of variability accounted for by common shocks. Prior to 1984, for example, idiosyncratic shocks played virtually no role in the variability of output growth in the sectors related to "Fabricated Metals: Forging and Stamping," or "Other Fabricated Metal Products". Furthermore, because the sectors in Table 4 move mainly with common shocks, and as we have just seen movements in the aggregate IP index are associated with these shocks, the sectors listed in Table 4 turn out to be particularly informative about the IP index.

Consider, for instance, the problem of tracking movements in IP in real time using only a subset $M$ of the IP sectors, say the five highest ranked sectors in Table $5 .{ }^{3}$ Let $\widetilde{X}_{t}$ represent the vector of output growth rates associated with these $M$ sectors such that $\widetilde{X}_{t}=\mathbf{s} X_{t}$, where $\mathbf{s}$ is a corresponding $M \times N$ selection matrix. To assess the information content of IP embodied in those $M$ sectors, weights are simply determined by the orthogonal projection of $g_{t}$ on $\widetilde{X}_{t}, E\left(\mathbf{w}^{\prime} X_{t} \mid \widetilde{X}_{t}\right)=\widetilde{X}_{t} \psi$. Specifically, the $M \times 1$ vector of weights $\psi$ is given by $\psi=\left(\mathbf{s} \Sigma_{X X} \mathbf{s}^{\prime}\right)^{-1} \mathbf{s} \Sigma_{X X} \mathbf{w}$. Table 5 then shows that estimates of $\widetilde{X}_{t} \psi$ computed with only the five highest ranked sectors in Table 4 are enough to explain the bulk of the variation in IP. Prior to 1984, these five sectors alone account for 85 percent of the variation in the growth rate of the aggregate index. In addition, 99 percent of the variability in IP growth rates is captured by considering only the thirty highest ranked sectors (out of 117) over 19721983. This fraction is somewhat smaller at 90 percent over the Great Moderation period. In either case, however, it is apparent that information about movements in IP turns out to be concentrated in a small number of sectors. Contrary to conventional wisdom, these

\footnotetext{
${ }^{3} \mathrm{IP}$ numbers are typically released with a one month lag, revised up to three months after their initial release, and further subject to an annual revision. Both to confirm initial releases and to independently track economic activity, the Institute for Supply Management constructs an index of manufacturing production based on nationwide surveys. In addition, several Federal Reserve Banks including Dallas, Kansas City, New York, Philadelphia, and Richmond, produce similar indices that are meant to capture real time changes in activity at a more regional level. Of course, a central issue pertaining to these surveys is that gatehering information on a large number of sectors in a timely fashion is costly, so that the scope of the surveys is generally limited.
} 
sectors are not necessarily those with the largest weights, the most volatile output growth, nor the most links to other sectors (e.g. Electric Power Generation"). Since aggregate IP is driven mainly by common shocks, what matters is that those sectors also move with common shocks. We return to this point in the next section.

What do we learn from these results about the variability of aggregate IP growth rates? Common shocks largely explain changes in aggregate IP, and a decrease in the volatility of these shocks explains why aggregate IP is considerably less variable after 1984. In addition, information about changes in the aggregate IP index is condensed in a small number of sectors.

\section{Structural Factor Analysis}

An important assumption underlying the consistent estimation of factors in the previous section was that the covariance matrix of the uniquenesses, $u_{t}$, in equation (1) satisfy weak cross sectional dependence. However, as discussed in Long and Plosser (1983), Horvath (1998), Carvalho (2007), and elsewhere, input-output linkages between the industrial sectors may lead to the propagation of sector-specific shocks throughout the economy in a way that generates comovement across sectors. In other words, these input-output linkages may, effectively, transform shocks that are specific to particular sectors into common shocks, and thereby explain in part the variability of aggregate output. As discussed in Horvath (1998) and Dupor (1999), the strength of this amplification mechanism depends importantly on the structure of the input-output matrix governing linkages between sectors.

In this section, we use BEA estimates of the input-output matrix linking production sectors in the U.S. to quantify the effects of shock propagation on the volatility of the aggregate IP index. Because this calculation requires a model that incorporates linkages between sectors, the first subsection describes a generalization of the framework first introduced in Horvath (1998) that will be used. This framework extends that used by Long and Plosser (1983) by considering capital along with non-storable intermediate inputs, and is effectively a multisector version of the original Brock-Mirman (1972) one sector growth model. The key feature of interest is that production in each sector uses materials produced in the other sectors. Therefore, shocks to an individual sector may be disseminated to other sectors and over time in a way that potentially contributes to aggregate fluctuations. This subsection then describes conditions under which the factor model in (1) may, in fact, be interpreted as a reduced form of the structural model with input-output linkages. It also illustrates how 
the structural model may be used to filter out the effects of these linkages. The following subsection presents the quantitative results.

\subsection{A Canonical Model with Input-Output Linkages}

Consider an economy comprised of $N$ distinct sectors of production indexed by $j=1, \ldots, N$. Each sector produces a quantity $Y_{j t}$ of good $j$ at date $t$ using sector-specific capital, $K_{j t}$, labor, $L_{j t}$, and materials produced in the other sectors, $M_{i j t}$, according to the technology

$$
Y_{j t}=A_{j t} K_{j t}^{\alpha_{j}} \prod_{i=1}^{N} M_{i j t}^{\gamma_{i j}} L_{j t}^{1-\alpha_{j}-\sum_{i=1}^{N} \gamma_{i j}}
$$

where $A_{j t}$ is a productivity index for sector $j$.

The fact that each sector uses materials from other sectors represents the source of interconnectedness in the model. An input-output matrix for this economy is an $N \times N$ matrix $\Gamma$ with typical element $\gamma_{i j}$. The column sums of $\Gamma$ give the degree of returns to scale in materials in each sector. The row sums of $\Gamma$ measure the importance of each sector's output as materials to all other sectors. Put simply, we can think of the rows and columns of $\Gamma$ as "sell to" and "buy from" respectively for each sector. We denote the vector of capital shares by $\alpha_{d}=\left(\alpha_{1}, \alpha_{2}, \ldots, \alpha_{N}\right)^{\prime}$.

We let $A_{t}=\left(A_{1 t}, A_{2 t}, \cdots, A_{N t}\right)^{\prime}$ denote the vector of productivity indices, and assume that $\ln \left(A_{t}\right)$ follows the random walk,

$$
\ln \left(A_{t}\right)=\ln \left(A_{t-1}\right)+\varepsilon_{t}
$$

where $\varepsilon_{t}=\left(\varepsilon_{1 t}, \varepsilon_{2 t}, \ldots, \varepsilon_{N t}\right)^{\prime}$ is a vector-valued martingale difference process with covariance matrix $\Sigma_{\varepsilon \varepsilon}$. The degree to which sectoral productivity is influenced by aggregate shocks will be reflected in the matrix $\Sigma_{\varepsilon \varepsilon}$. When $\Sigma_{\varepsilon \varepsilon}$ is diagonal, sectoral productivity is affected only by idiosyncratic shocks.

A representative agent derives utility from the consumption of these $N$ goods according to

$$
E_{t} \sum_{t=0}^{\infty} \beta^{t} \sum_{j=1}^{N}\left(\frac{C_{j t}^{1-\sigma}-1}{1-\sigma}-\psi L_{j t}\right)
$$

where the labor specification follows Hansen's (1985) indivisible labor model. In addition, each sector is subject to the following resource constraint,

$$
C_{j t}+\sum_{i=1}^{N} M_{j i t}+K_{j t+1}-(1-\delta) K_{j t}=Y_{j t}, \quad j=1, \ldots, N
$$


This model is essentially that introduced by Horvath (1998) extended to allow for elastic labor supply, less than full capital depreciation, and non-log preferences.

Details of the model solution to the planner's problem are available in a separate technical appendix [Foerster, Sarte, and Watson (2008)]. While the model in Horvath (1998) admits an analytical solution, that model's assumption of full capital depreciation within the quarter, in particular, makes it somewhat unsuitable for the purposes of an empirical investigation. The companion appendix shows that in the generalized version adopted here, the deterministic steady state of the model continues to be analytically tractable. ${ }^{4}$ Furthermore, using a linear approximation of the model's first-order conditions and resource constraints around that steady state, one can show that the vector of sectoral output growth, $X_{t}=\left(\Delta \ln \left(Y_{1 t}\right), \Delta \ln \left(Y_{2 t}\right), \ldots, \Delta \ln \left(Y_{N t}\right)\right)^{\prime}$ evolves according to

$$
X_{t}=\Phi X_{t-1}+\Pi \varepsilon_{t}+\Xi \varepsilon_{t-1}
$$

where $\Phi, \Pi$, and $\Xi$ are $N \times N$ matrices that depend only on the model parameters, $\alpha_{d}, \Gamma$, $\beta, \sigma, \psi$, and $\delta$.

Suppose that innovations to sectoral productivity, $\varepsilon_{j t}$, reflect both aggregate shocks, $S_{t}$, and idiosyncratic shocks, $v_{j t}$, such that

$$
\varepsilon_{t}=\Lambda_{s} S_{t}+v_{t}
$$

The matrix $\Lambda_{s}$ governs the degree to which aggregate disturbances affect productivity in individual sectors; when there are $k$ aggregate factors in $S_{t}, \Lambda_{s}$ is $N \times k$. The vector of disturbances, $v_{t}=\left(v_{1 t}, v_{2 t}, \ldots, v_{n t}\right)^{\prime}$, captures idiosyncratic shocks that are uncorrelated across sectors and has diagonal covariance matrix $\Sigma_{v v}$.

Given equations (6) and (7), and denoting the lag operator by $\mathbf{L}$, the evolution of sectoral output growth can be written as

$$
X_{t}=\Lambda F_{t}+u_{t},
$$

where $\Lambda(\mathbf{L})=(I-\Phi \mathbf{L})^{-1}(\Pi+\Xi \mathbf{L}) \Lambda_{s}, F_{t}=S_{t}$, and $u_{t}=(I-\Phi \mathbf{L})^{-1}(\Pi+\Xi \mathbf{L}) v_{t}$. In other words, the vector of sectoral output growth rates in this multisector extension of the standard growth model produces an approximate factor model as a reduced form. The common factors in this reduced form are associated with aggregate shocks to sectoral productivity while the "uniquenesses" reflect linear combinations of the underlying structural sector-specific shocks. In particular, the key issue is that input output linkages between sectors will induce some

\footnotetext{
${ }^{4}$ This feature is helpful since, in simulations of the model, it avoids having to solve for a large set of non-linear equations involving117 sectors (e.g. there are 13,689 steady state $M_{i j}$ allocations).
} 
cross-sectional dependence among the "uniquenesses" that may cause the statistical factor model to overestimate the importance of aggregate shocks. This is most transparent in the special case initially studied by Horvath (1998) with no labor, full depreciation, and log preferences. In that case, the model's exact solution is given by (6) with $\Phi=\left(I-\Gamma^{\prime}\right)^{-1} \alpha_{d}$, $\Xi=0$, and $\Pi=\left(I-\Gamma^{\prime}\right)^{-1}$, so that

$$
u_{t}=\left(I-\left(I-\Gamma^{\prime}\right)^{-1} \alpha_{d} \mathbf{L}\right)^{-1}\left(I-\Gamma^{\prime}\right)^{-1} v_{t} .
$$

Therefore, while sector specific shocks $v_{t}$ in the equation above have a diagonal covariance matrix $\Sigma_{v v}$, the "uniquenesses," $u_{t}$, will exhibit some degree of cross-sectional dependence induced by the input-output matrix $\Gamma$. Furthermore, by ignoring the comovement in "uniquenesses," the factor model would incorrectly attribute any resulting comovement in sectoral output growth to aggregate shocks.

To eliminate the propagation effects of sector specific shocks induced by input-output linkages, we filter the vector of data on sectoral output growth to construct $\varepsilon_{t}$ where, from equation (6),

$$
\varepsilon_{t}=(\Pi+\Xi \mathbf{L})^{-1}(I-\Phi \mathbf{L}) X_{t} .
$$

We can then apply factor analytic methods to the constructed series for $\varepsilon_{t}$ to recover the relative contribution of aggregate shocks, $S_{t}$, and sector specific shocks, $v_{t}$, to the variability of aggregate output.

\subsection{Calibrating the Model Parameters}

We shall interpret the model as describing the sectoral production indices analyzed in sections 2 and 3. Thus, we abstract from output of the service and public sectors. In addition, because the model does not take into account delivery lags that would undoubtedly be relevant at the monthly frequency, this section focuses on quarterly data.

In order to construct the filtered series described in equation (10), we must first calibrate the model's parameters. A subset of these parameters is standard and chosen in accordance with previous work on business cycles. Thus, given our focus on quarterly data, we set $\beta=0.99$ and $\delta=0.025$. We further set $\sigma=1$ and $\psi=1$ as a benchmark. While we treat these parameters as constant through time, the choice of input-output matrix, $\Gamma$, requires more caution. In particular, we wish to capture the model's implications for the filtered series, $\varepsilon_{t}$, in equation (10) arising from potential low frequency changes in the structure of U.S. production. 
The calibration of the parameters describing technology $\left(\gamma_{i j}\right.$ and $\left.\alpha_{j}\right)$ derives from estimates of input-output tables supplied by the BEA. We use 117 sectors (i.e. $N=117$ ) which corresponds roughly to a four-digit level of disaggregation. The BEA "Input Use" tables measure the value of inputs in producer prices, given by commodity codes, used by each industry, described by industry codes. By matching commodity and industry codes, we obtain the value of inputs from each industry used by every other industry. Moreover, the input-output tables include compensation of employees (wages) and other value added (rents on capital). We abstract from non-IP sectors, which include agriculture, services, and government. A column sum in the input-output table represents total payments from a given sector to all other sectors (i.e. material inputs, labor, and capital) and defines the value of output in that sector. A row sum in the input-output table gives the importance of a given sector as an input supplier to all other sectors, measured as the value of inputs in other sectors' production. Hence, input shares, $\gamma_{i j}$, are calibrated as dollar payments from industry $j$ to industry $i$ expressed as a fraction of the value of production in sector $j$. Similarly, capital shares for the $j$-th industry reflect dollar payments to capital as a fraction of the value of output in sector $j$.

To account for changes in the structure of U.S. input-output linkages before and after the Great Moderation, we consider two BEA benchmark years, 1977 and 1998. BEA benchmark tables are available only every five years but disaggregated more finely than tables available in non-benchmark years. Unfortunately, as discussed in Section 2, the input-output tables for the years prior to 1997 are not updated by the BEA to reflect the reclassification of industries by NAICS definitions, and are broken down instead according to SIC codes. For consistency, therefore, we include in our analysis vintage IP data provided by the Board of Governors where sectors are disaggregated by SIC codes, and which cover the period 1967-2002. We use these two data sources, and contrast the results associated with each, throughout the remainder of the paper. Finally, the remaining set of parameters that need to be estimated are those making up $\Sigma_{\varepsilon \varepsilon}$, the covariance matrix of the structural productivity shocks, $\varepsilon_{t}$.

We choose two calibrations for $\Sigma_{\varepsilon \varepsilon}$ that help highlight the degree to which the model is able propagate purely idiosyncratic shocks, and thus effectively transform these shocks into common shocks. In the first calibration, $\Sigma_{\varepsilon \varepsilon}$ is a diagonal matrix with entries given by the sample variance of $\varepsilon_{t}$ in the different IP sectors, where $\varepsilon_{t}$ is computed from equation (10) using quarterly sectoral production data on $X_{t}$. The sample variance of $\varepsilon_{t}$ is computed over different sample periods and using different data vintages (e.g. 1972-1983, 1984-2007 using IP data defined by NAICS codes) to account for heteroskedasticity that may be important for 
the Great Moderation. Because this calibration uses uncorrelated sectoral shocks, it allows us to determine whether input-output linkages per se can explain the strong covariance in sectoral production that is necessary to generate the variability in aggregate output.

In the second calibration, we use a factor model to represent $\Sigma_{\varepsilon \varepsilon}$. That is, we model $\varepsilon_{t}$ as shown in equation (7) where, as in the last section, $S_{t}$ is a $k \times 1$ vector of common factors and $v_{t}$ is an $N \times 1$ vector of mutually uncorrelated sector-specific idiosyncratic shocks. In this model, $\Sigma_{\varepsilon \varepsilon}=\Lambda_{s} \Sigma_{S S} \Lambda_{s}^{\prime}+\Sigma_{v v}$, where $\Lambda_{s}$, and the covariance matrices $\Sigma_{S S}$ and $\Sigma_{v v}$, are estimated using the principal components estimator of $S_{t}$ constructed from the sample values of $\varepsilon_{t}$. This second calibration allows two sources of covariance in sectoral output: a structural component arising from input-output linkages and a statistical component arising from aggregate shocks affecting sectoral productivity.

\subsection{Results From the Structural Analysis}

\subsubsection{Comovement from Input-Output Linkages}

Table 6 summarizes key results for the model when sectoral shocks are driven only by idiosyncratic shocks that are cross-sectionally uncorrelated (i.e., $\Sigma_{\varepsilon \varepsilon}$ is diagonal). The table compares average pairwise correlations of sectoral output growth rates implied by the model with those calculated in the data. It also contrasts the standard deviation of aggregate IP implied by the model with that in the data. The matrix $\Sigma_{\varepsilon \varepsilon}$ is calibrated over the samples before and after the Great Moderation, and using both 1977 and 1998 input-output matrices corresponding to SIC and NAICS sectoral decompositions respectively.

Table 6 makes several observations apparent. First, the data vintage is immaterial for the calculations of average pairwise correlations despite the fact the vintages span different pre- and post-Great Moderation sample periods. Irrespective of the vintage, one observes a notable fall in the average pairwise correlation, and thus comovement, of sectoral growth rates from roughly 0.27 in the first sample period to 0.11 after 1984 . Second, the model with input-output linkages and uncorrelated sector-specific shocks implies significantly less comovement across sectors than in U.S. data. The model, therefore, falls considerably short of matching the variability of aggregate IP growth rates. To get a sense of the quantitative contribution of input-output linkages to aggregate IP variability, consider, for instance, the data broken down by NAICS definitions. Over the 1972-1983 period, the model explains 17 percent of the variance in aggregate IP growth rates $\left(0.17=(3.7 / 8.9)^{2}\right)$. In contrast, Table 2 indicates that the diagonal elements of the covariance matrix of sectoral IP growth rates 
account for roughly 7 percent of aggregate IP variance $\left(0.07=(2.4 / 8.9)^{2}\right)$. The difference $(0.17-0.07)$ represents the contribution of input-output linkages to aggregate variability. Similarly, over the 1984-2007 period, Table 6, panel (a), shows that the model explains 37 percent of the variance in aggregate IP growth rates. The diagonal elements of the covariance matrix used in Table 2, in contrast, account for 17 percent of the variability in aggregate IP. It appears, therefore, that the model with uncorrelated idiosyncratic shocks explains a somewhat larger fraction of aggregate variability after the Great Moderation. As a mechanical matter, because the same input-output matrix is used for the calculations in both sample periods, the increased relative importance of sector-specific shocks does not arise from changes in input-output linkages. Rather, they reflect a fall in the variability of aggregate shocks after 1984 .

Table 7, panels (a) and (b), present an alternative way of assessing the comovement implied by the structural model with uncorrelated sector-specific shocks. In particular, the table compares the eigenvalues of the correlation matrix of sectoral growth rates in the data with selected percentiles of the distribution of eigenvalues obtained from sample correlation matrices computed from model-simulated data. ${ }^{5}$ The data indicate one or two dominant eigenvalues followed by eigenvalues of similar magnitudes. This pattern is consistent with a factor model characterized by one or two common factors. Indeed, the Bai-Ng estimator of the number of common factors is based on these eigenvalues, and the results in Table 7 explain why the Bai-Ng estimator finds two factors in the first sample period and one factor in the second. In contrast, as the percentiles suggest, data generated from model simulations using a diagonal covariance matrix, $\Sigma_{\varepsilon \varepsilon}$, are very unlikely to exhibit this pattern. Although associated with some limited comovement, the eigenvalues of the sample correlation matrices are generally of similar magnitude both across sample periods and across input-output matrix definitions. Interestingly, therefore, changes in the structure of input-output relationships between 1977 and 1998 have not lead to greater propagation of idiosyncratic shocks. This is also consistent with the fact that in Table 6, average pairwise correlations of sectoral growth rates from the model are similar both across sample periods and across input-output matrix definitions.

Table 8 presents the same results as those shown in Table 6 , but for the case where $\Sigma_{\varepsilon \varepsilon}$ is constructed from a specification with two common factors, so that $\Sigma_{\varepsilon \varepsilon}=\Lambda_{s} \Sigma_{S S} \Lambda_{s}^{\prime}+\Sigma_{v v}$ from equation (7). The factors are estimated using the same method as in section 3 applied

\footnotetext{
${ }^{5}$ The percentiles were computed by Monte Carlo methods from the model with Gaussian errors and using 5000 draws. Results using the empirical distribution of errors computed from the U.S. data via equation (10) yielded similar results.
} 
to the filtered series $\varepsilon_{t}$ from equation (10). In contrast to the results shown in Table 6, allowing aggregate shocks to affect sectoral productivity enables the model to capture the average pairwise cross-correlation in sectoral growth rates found in the data, and produces an aggregate IP index that is as volatile as in the U.S. data. In addition, Table 9 indicates that the structural model now generates sample correlation matrices with eigenvalues much like those found in the U.S. data.

\subsubsection{Idiosyncratic vs. Aggregate Shocks}

What then are the implications of the structural model for the relative importance of aggregate and sector-specific shocks? Table 10 compares the fractions of IP variance explained by aggregate shocks, $S_{t}$, in the structural model with those explained by common shocks, $F_{t}$, in the statistical model of section 2. Three key results stand out. First, because the comovement in sectoral growth rates is in part generated by way of input-output linkages, aggregate shocks explain a somewhat lower fraction aggregate IP variability in the structural model than in the statistical model. The difference, however, is small prior to the Great Moderation although somewhat more pronounced after 1984. On the whole, the statistical factor model represents a relatively robust way of capturing aggregate shocks. Second, aggregate productivity shocks explain the bulk of fluctuations in aggregate IP, although less so after the Great Moderation. Interestingly, the fraction of aggregate IP variance explained by sector-specific shocks nearly doubles, to approximately 30 percent, in the second sample period. This result is driven mainly by a fall in the variability of aggregate shocks, $S_{t}$, over this second period. Finally, the fall in the variability of $S_{t}$ also explains nearly all of the decline in the post-1984 variance of aggregate IP growth rates.

Given the increase in the relative importance of sector specific shocks over the Great Moderation period, Table 11 lists the sectors whose idiosyncratic shocks ( $v_{t}$ in the structural model above) explain the highest fraction of aggregate IP variability. To account for changes in the structure of U.S. production, idiosyncratic shocks are constructed using the 1977 input-output matrix for the period 1967-1983 and the 1998 input-output matrix over 19842007. The table highlights several facts. First, the highest ranked sectors tend to be those that serve as inputs to many other sectors. This is the case, for example, of "Basic Steel and Mill Products" in the pre-1984 period (6.4 percent), which corresponds to "Iron and Steel Products" after 1984 (4.2 percent). It is also true of "Utilities" prior to 1984, which corresponds approximately to "Electric Power Generation and Distribution" in the second sample period. Second, because of the reduced variability of aggregate shocks in the post- 
1984 period, individual sectors can play a measurable role in IP fluctuations after 1984. Prior to 1984, there were only two sectors whose idiosyncratic shocks alone explained more than 1 percent of the variation in aggregate IP growth rates. In contrast, all sectors in Table 11, panel (b), now have idiosyncratic shocks that independently explain more than 1 percent of aggregate IP fluctuations. Finally, Table 11 points to some changes in the structure of U.S. production. For example, "Coal Mining", a traditional industry ranked second prior to 1984 (at 3.4 percent), is no longer among the highest ten ranked sectors in the second sample period. Similarly, "Electronic Components" moved up in the ranking (from 0.2 percent to 2.6 percent) and "Aerospace Products and Parts", becomes one of the sectors whose idiosyncratic behavior matters most (1.5 percent) in the post-1984 period.

\subsubsection{Additional Considerations}

Although sector-specific shocks have played a relatively greater role in driving aggregate IP movements since 1984, it remains that the principal source of variation in IP stems from aggregate shocks. This is why the sectors listed in Table 4 ultimately do a better job of tracking IP movements than those listed in Table 11. The result concerning aggregate shocks as a dominant source of variation in IP is in part related to the structure of the input-output matrix for U.S. production, but it also reflects the way in which this matrix interacts with other parameters of the structural model. For example, assuming that capital depreciates fully within the period (i.e. $\delta=1$ ), Horvath (1998) finds that independent sector-specific shocks contribute an important fraction of aggregate volatility. For comparison, therefore, Table 12, panels (a) and (b), contrasts the findings under our benchmark calibration, $\delta=$ 0.025 , with those that obtain with full depreciation, $\delta=1$. As expected, setting $\delta=1$ noticeably increases the fraction of variability in IP growth rates explained by idiosyncratic shocks, especially in the second sample period. Consistent with this finding, the average pairwise correlation of output growth across sectors generated by purely idiosyncratic shocks (i.e. 0 factors), essentially doubles when $\delta=1$. To see why this is the case, recall equation (5) and move the undepreciated capital to the other side of the equation to define a broad notion of technology,

$$
\tilde{Y}_{j t}=A_{j t} K_{j t}^{\alpha_{j}} \prod_{i=1}^{N} M_{i j t}^{\gamma_{i j}} L_{j t}^{1-\alpha_{j}-\sum_{i=1}^{N} \gamma_{i j}}+(1-\delta) K_{j t} .
$$

When $\delta$ is small, as in our benchmark calibration, a considerable part of a given sector's production does not respond contemporaneously to its own idiosyncratic shocks. This is also true of aggregate shocks but these affect all sectors in the same way. In contrast, when $\delta=1$, 
the second term in (11) vanishes and idiosyncratic shocks have a more direct effect on $\widetilde{Y}_{j t}$. In the filtering process, therefore, a greater portion of fluctuations in sectoral output growth is attributed to idiosyncratic shocks, which are then propagated by way of input-output linkages. This will then be reflected in an increase of pairwise correlations of output growth rates across sectors.

Finally, Table 13 shows how our findings for the benchmark model change with the level of data disaggregation. In this exercise, we use the 1998 input-output matrix and corresponding IP data since they provide the highest degree of disaggregation. As the data become less disaggregated, average pairwise correlations of sectoral IP growth rates increase both in the data and in the structural model. ${ }^{6}$ As a result, the fraction of variability in aggregate IP growth rates explained by aggregate shocks remains essentially unchanged across levels of disaggregation.

\section{Concluding Remarks}

In this paper, we explore various leading explanations underlying the volatility of industrial production and its decline since 1984. We find that neither time variation in the sectoral shares of IP nor their distribution are important factors in determining the variability of the aggregate IP index. Instead, the analysis reveals that aggregate shocks largely explain changes in aggregate IP, and a decrease in the volatility of these shocks explains why aggregate IP is considerably less variable after 1984. Because of this decline in the variability of aggregate shocks, the relative importance of sector-specific shocks has more than doubled over the Great Moderation period. Specifically, while sector-specific shocks explain approximately 12 percent of the variation in IP growth prior to 1984, they account for about 30 percent of IP fluctuations after the onset of the Great Moderation. We have also shown that changes in the structure of the input-output matrix between 1977 and 1998 have not lead to a more pronounced propagation of sectoral shocks.

The analysis also highlights the conditions under which neoclassical multisector growth models of the type first studied by Long and Plosser (1983) admit an approximate factor model as a reduced form. In doing so, it bridges two literatures, one that has relied on factor analytic methods to assess the relative importance of aggregate and idiosyncratic shocks, and the other rooted in more structural calibrated models that explicitly take into account input-

\footnotetext{
${ }^{6}$ This is not surprising since movements in output growth across more broadly defined sectors will reflect common shocks to their constituent sectors.
} 
output linkages across sectors. In the reduced form factor model, aggregate shocks emerge as the common output factors. The "uniquenesses" are associated with sector specific shocks but, because of input-output linkages, these can be cross sectionally correlated. A generalized version of the model studied by Horvath (1998), however, suggests that the degree of sectoral comovement generated by input-output linkages is limited. 


\section{References}

[1] Anderson, T. W. (1984), "An Introduction to Multivariate Statistical Analysis," Second Edition (Wiley, New York).

[2] Brock W. and L. Mirman (1972), "Optimal economic growth and uncertainty: The discounted case," Journal of Economic Theory, 4:479-513.

[3] Carvalho, V. M. (2007), "Aggregate fluctuations and the network structure of intersectoral trade," manuscript, University of Chicago.

[4] Bai, J. (2003), "Inferential theory for factor models of large dimensions," Econometrica, 71:135-171.

[5] Bai, J., and S. Ng (2002), "Determining the number of factors in approximate factor models," Econometrica, 70:191-221.

[6] Chamberlain, G., and M. Rothschild (1983), "Arbitrage factor structure, and meanvariance analysis of large asset markets," Econometrica, 52:1281-1304.

[7] Connor, G., and R. A. Korajczyk (1986), "Performance measurement with the arbitrage pricing theory," Journal of Financial Economics, 15:373-394.

[8] Connor, G., and R. A. Korajczyk (1988), "Risk and return in an equilibrium APT: application of a new test methodology," Journal of Financial Economics, 21:255-289.

[9] Dupor, B. (1999), "Aggregation and irrelevance in multi-sector models," Journal of Monetary Economics, 43:391-409.

[10] Gabaix, X. (2005), "The granular origins of aggregate fluctuations," manuscript, Massachusetts Institute of Technology.

[11] Hansen, G. (1985), "Indivisible labor and the business cycle," Journal of Monetary Economics, 16:309-337.

[12] Horvath, M. (1998) "Cyclicality and sectoral linkages: aggregate fluctuations from independent sectoral shocks," Review of Economic Dynamics, 1:781-808.

[13] Horvath, M. (2000), "Sectoral shocks and aggregate fluctuations," Journal of Monetary Economics, 45:69-106. 
[14] Long JR, J. and C. I. Plosser (1983), "Real business cycles," Journal of Political Economy, 91:39-69.

[15] Long JR, J. and C. I. Plosser (1987), "Sectoral vs. aggregate Shocks in the business cycle," American Economic Review, 77:333-336.

[16] Foerster, A., Sarte, P-D., and M. W. Watson (2008), "Supplementary material for: Sectoral vs. aggregate shocks: A structural factor analysis of industrial production," available at http://www.princeton.edu/ ${ }^{\sim}$ mwatson.

[17] Forni, M., and L. Reichlin (2000), "The generalized factor model: identification and estimation," The Review of Economics and Statistics 82:540-554.

[18] Forni, M., and L. Reichlin (1998), "Let's get real: a dynamic factor analytical approach to disaggregated business cycle," Review of Economic Studies, 65:453-474.

[19] Quah, D., and T. J. Sargent (1993), "A dynamic index model for large cross sections," in: J. H. Stock and M. W. Watson, eds., Business Cycles, Indicators, and Forecasting, (University of Chicago Press for the NBER, Chicago), Ch. 7.

[20] Shea, J. (2002) "Complementarities and Comovements," Journal of Money, Credit, and Banking, 34:412-433.

[21] Stock, J. H. and M. W. Watson (2000), "Forecasting using principal components from a large number of predictors," Journal of the American Statistical Association 97: 11671179. 


\section{Appendix A}

Data on Industrial Production is obtained from the Board of Governors of the Federal Reserve System and disaggregated according to the North American Industry Classification System (NAICS). The raw data are indices of real output, from which we compute sectoral growth rates and sectoral shares in aggregate IP. While data on the vast majority of sectors is directly available from the Board of Governors, growth rates for any missing sectors are approximated using the Board's recommended methodology. For example, if industry $C$ is composed of industry $A$ and industry $B$, then the growth rate of $C$ 's output is approximated by

$$
\frac{I P_{C t}}{I P_{C t-1}}=\frac{W_{A t-1} \frac{I P_{A t}}{I P_{A t-1}}+W_{B t-1} \frac{I P_{B t}}{I P_{B t-1}}}{W_{A t-1}+W_{B t-1}}
$$

where $W_{i t-1}$ is the share of industry $i$ at date $t-1$, and $W_{C t-1}=W_{A t-1}+W_{B t-1}$. Alternatively, if industry $C$ is made up of industry $A$ less industry $B$, then

$$
\frac{I P_{C t}}{I P_{C t-1}}=\frac{W_{A t-1} \frac{I P_{A t}}{I P_{A t-1}}-W_{B t-1} \frac{I P_{B t}}{I P_{B t-1}}}{W_{A t-1}-W_{B t-1}},
$$

and $W_{C t-1}=W_{A t-1}-W_{B t-1}$. As mentioned in the text, we also make use of vintage IP data, provided by the Board of Governors, which are disaggregated according to Standard Industry Classification (SIC) codes. Growth rates and shares for missing sectors are computed in the manner we have just described. A basic summary of the IP data is provided in Table A1.

Benchmark Input-Output tables, available every five years, are obtained from the Bureau of Economic Analysis. The "Use Table" measures the value of inputs in producer prices, given by commodity codes, used by each industry, given by industry codes, as well as payments to other factors such as labor and capital. The original data are in the most disaggregated format, and we aggregate industries by adding dollar values for these industries. We consider benchmark tables for 1977 and 1997 which are broken down according SIC and NAICS industry definitions respectively.

In order to match the input-output matrices with IP data, we aggregate or disaggregate the two data types until the smallest industry level for which both data sources are available is found. Put another way, we find the smallest set of common industries for which we can match both IP and input-output data. Because the two data sources are originally disaggregated to different levels, the sectoral breakdown we end up using represents collections of either NAICS or SIC industry levels (depending on whether we are using current or vintage IP data). The approach is as follows: taking the finest available partition of industries from the benchmark input-output tables, we match up as many industries as possible; the 
remaining industries with no matches are aggregated until a match is found. The result are collections of industries whose level of disaggregation ranges from 2-digit to 5-digit levels. Results reported in the text are for the highest level of disaggregation available, the 5-digit level, unless otherwise stated.

Data from the 1997 input-output table are matched with IP data disaggregated using NAICS definitions over the period 1972Q1-2007Q4. Similarly, data from the 1977 inputoutput Table are matched with IP data broken down by SIC code from 1967Q1-2002Q3. The reclassification of industries from the SIC system to the NAICS system, and the fact that older input-output tables are not updated according to NAICS definitions, makes the use of vintage IP data necessary since there is no easy mapping from SIC to NAICS definitions. 
Table A1

117 Sectors NAICS Industry Classification

\begin{tabular}{|c|c|c|c|}
\hline \multirow[t]{2}{*}{ Sector } & \multirow[t]{2}{*}{ Weight } & \multicolumn{2}{|c|}{$\begin{array}{c}\text { Standard Deviation of } \\
\text { Quarterly Growth Rates } \\
\text { (PAAR) }\end{array}$} \\
\hline & & $1972-1983$ & $1984-2007$ \\
\hline Logging & 0.27 & 17.9 & 14.2 \\
\hline Oil and Gas Extraction & 5.79 & 3.8 & 5.7 \\
\hline Coal Mining & 1.06 & 79.7 & 15.4 \\
\hline Iron Ore Mining & 0.09 & 132.0 & 37.9 \\
\hline Gold, Silver, and Other Ore Mining & 0.16 & 30.3 & 22.0 \\
\hline Copper, Nickel, Lead, and Zinc Mining & 0.15 & 61.4 & 14.2 \\
\hline Nonmetallic Mineral Mining and Quarrying & 0.63 & 14.3 & 10.4 \\
\hline Support Activities for Mining & 1.06 & 20.6 & 28.6 \\
\hline Electric Power Generation, Transmission and Distribution & 7.65 & 8.0 & 6.9 \\
\hline Natural Gas Distribution & 1.65 & 16.0 & 16.7 \\
\hline Animal Food & 0.41 & 8.1 & 10.3 \\
\hline Grain and Oilseed Milling & 0.77 & 12.4 & 8.9 \\
\hline Sugar and Confectionery Products & 0.55 & 23.4 & 12.0 \\
\hline Fruit and Vegetable Preserving and Specialty Foods & 1.03 & 9.6 & 11.3 \\
\hline Dairy Products Ex Frozen & 0.72 & 4.8 & 7.4 \\
\hline Ice Cream and Frozen Desserts & 0.11 & 9.7 & 12.8 \\
\hline Animal Slaughtering and Processing & 1.29 & 10.4 & 6.3 \\
\hline Seafood Product Preparation and Packaging & 0.14 & 28.6 & 24.6 \\
\hline Bakeries and Tortilla & 1.23 & 4.3 & 4.2 \\
\hline Coffee and Tea & 0.18 & 39.0 & 17.7 \\
\hline Other Food Except Coffee and Tea & 0.95 & 11.1 & 7.1 \\
\hline Soft Drinks and Ice & 0.60 & 7.5 & 8.9 \\
\hline Breweries & 0.45 & 14.7 & 9.1 \\
\hline Wineries and Distilleries & 0.26 & 26.6 & 20.5 \\
\hline Tobacco & 1.07 & 12.6 & 19.3 \\
\hline Fiber, Yarn, and Thread Mills & 0.22 & 23.6 & 15.3 \\
\hline Fabric Mills & 0.69 & 16.5 & 9.9 \\
\hline Textile and Fabric Finishing and Fabric Coating Mills & 0.31 & 17.5 & 11.6 \\
\hline Carpet and Rug Mills & 0.20 & 26.9 & 16.3 \\
\hline Curtain and Linen Mills & 0.16 & 18.3 & 12.6 \\
\hline Other Textile Product Mills & 0.20 & 16.4 & 8.7 \\
\hline Apparel & 1.83 & 10.8 & 8.9 \\
\hline Leather and Allied Products & 0.34 & 12.3 & 13.2 \\
\hline Sawmills and Wood Preservation & 0.44 & 25.8 & 11.3 \\
\hline Veneer, Plywood, and Engineered Wood Products & 0.33 & 26.9 & 12.1 \\
\hline Millwork & 0.34 & 21.1 & 9.0 \\
\hline Wood Containers and Pallets & 0.08 & 12.2 & 8.7 \\
\hline All Other Wood Products & 0.29 & 26.8 & 15.9 \\
\hline Pulp Mills & 0.08 & 16.7 & 10.8 \\
\hline Paper and Paperboard Mills & 1.59 & 16.0 & 6.2 \\
\hline Paperboard Containers & 0.71 & 15.7 & 6.6 \\
\hline Paper Bags and Coated and Treated Paper & 0.39 & 11.4 & 10.0 \\
\hline Other Converted Paper Products & 0.37 & 15.1 & 8.3 \\
\hline Printing and Related Support Activities & 2.30 & 7.2 & 4.9 \\
\hline Petroleum Refineries & 1.66 & 13.9 & 7.6 \\
\hline Paving, Roofing, and Other Petroleum and Coal Products & 0.33 & 17.8 & 11.3 \\
\hline Organic Chemicals & 1.39 & 19.0 & 12.8 \\
\hline Industrial Gas & 0.21 & 19.9 & 17.7 \\
\hline Synthetic Dyes and Pigments & 0.15 & 30.9 & 16.8 \\
\hline Other Basic Inorganic Chemicals & 0.57 & 26.7 & 21.7 \\
\hline Resins and Synthetic Rubber & 0.79 & 32.9 & 11.4 \\
\hline Artificial and Synthetic Fibers and Filaments & 0.34 & 38.4 & 12.9 \\
\hline Pesticides, Fertilizers, and Other Agricultural Chemicals & 0.49 & 12.9 & 10.1 \\
\hline Pharmaceuticals and Medicines & 2.52 & 5.6 & 6.7 \\
\hline Paints and Coatings & 0.40 & 18.3 & 13.7 \\
\hline Adhesives & 0.13 & 16.7 & 11.2 \\
\hline Soap, Cleaning Compounds, and Toilet Preparation & 1.42 & 9.8 & 9.3 \\
\hline Other Chemical Product and Preparation & 0.94 & 10.4 & 9.6 \\
\hline
\end{tabular}




\begin{tabular}{|c|c|c|c|}
\hline Plastics Products & 2.27 & 16.8 & 6.0 \\
\hline Tires & 0.44 & 44.9 & 14.0 \\
\hline Rubber Products Ex Tires & 0.40 & 20.0 & 7.8 \\
\hline Pottery, Ceramics, and Plumbing Fixtures & 0.12 & 14.7 & 12.5 \\
\hline Clay Building Materials and Refractories & 0.16 & 22.7 & 16.9 \\
\hline Glass and Glass Products & 0.63 & 11.7 & 6.9 \\
\hline Cement & 0.19 & 28.0 & 16.8 \\
\hline Concrete and Products & 0.68 & 13.6 & 9.2 \\
\hline Lime and Gypsum Products & 0.11 & 19.1 & 17.1 \\
\hline Other Nonmetallic Mineral Products & 0.37 & 16.3 & 8.2 \\
\hline Iron and Steel Products & 1.70 & 41.5 & 19.5 \\
\hline Alumina and Aluminum Production and Processing & 0.52 & 17.6 & 13.4 \\
\hline Nonferrous Metal Smelting and Refining [Ex Aluminum] & 0.13 & 50.6 & 19.0 \\
\hline Copper and Nonferrous Metal Rolling, Drawing, Extruding, and Alloying & 0.35 & 41.2 & 17.4 \\
\hline Foundries & 0.79 & 19.5 & 9.1 \\
\hline Fabricated Metals: Forging and Stamping & 0.50 & 16.7 & 8.0 \\
\hline Fabricated Metals: Cutlery and Handtools & 0.35 & 15.0 & 8.0 \\
\hline Architectural and Structural Metal Products & 1.15 & 11.7 & 6.0 \\
\hline Boiler, Tank, and Shipping Containers & 0.59 & 9.1 & 6.6 \\
\hline Fabricated Metals: Hardware & 0.29 & 18.4 & 9.5 \\
\hline Fabricated Metals: Spring and Wire Products & 0.20 & 16.5 & 8.8 \\
\hline Machine Shops; Turned Products; and Screws, Nuts, and Bolts & 1.05 & 15.5 & 8.8 \\
\hline Coating, Engraving, Heat Treating, and Allied Activities & 0.40 & 11.6 & 9.4 \\
\hline Other Fabricated Metal Products & 1.33 & 10.9 & 5.8 \\
\hline Agricultural Implements & 0.50 & 22.0 & 27.6 \\
\hline Construction Machinery & 0.44 & 46.7 & 32.0 \\
\hline Mining and Oil and Gas Field Machinery & 0.29 & 28.4 & 21.9 \\
\hline Industrial Machinery & 0.74 & 11.9 & 20.5 \\
\hline Commercial and Service Industry Mach/Other Gen Purpose Mach & 2.19 & 11.8 & 6.2 \\
\hline Ventilation, Heating, Air-cond \& Commercial Refrigeration eq & 0.72 & 25.0 & 19.2 \\
\hline Metalworking Machinery & 0.86 & 19.0 & 9.7 \\
\hline Engine, Turbine, and Power Transmission Equipment & 0.80 & 20.2 & 14.9 \\
\hline Computer and Peripheral Equipment & 1.52 & 17.4 & 16.4 \\
\hline Communications Equipment & 1.55 & 10.7 & 16.6 \\
\hline Audio and Video Equipment & 0.19 & 37.7 & 43.4 \\
\hline Semiconductors and Other Electronic Components & 2.34 & 18.8 & 16.5 \\
\hline Navigational/Measuring/Electromedical/Control Instruments & 2.33 & 10.7 & 6.2 \\
\hline Magnetic and Optical Media & 0.20 & 28.0 & 21.6 \\
\hline Electric Lighting Equipment & 0.34 & 15.2 & 8.0 \\
\hline Small Electrical Household Appliances & 0.15 & 19.4 & 18.4 \\
\hline Major Electrical Household Appliances & 0.37 & 36.3 & 15.4 \\
\hline Electrical Equipment & 0.89 & 17.0 & 8.7 \\
\hline Batteries & 0.16 & 22.0 & 16.6 \\
\hline Communication and Energy Wires and Cables & 0.21 & 19.1 & 14.8 \\
\hline Other Electrical Equipment & 0.47 & 20.7 & 8.0 \\
\hline Automobiles and Light Duty Motor Vehicles & 2.32 & 51.2 & 24.8 \\
\hline Heavy Duty Trucks & 0.16 & 50.3 & 35.3 \\
\hline Motor Vehicle Bodies and Trailers & 0.41 & 29.9 & 17.1 \\
\hline Motor Vehicle Parts & 3.09 & 28.2 & 13.3 \\
\hline Aerospace Products and Parts & 3.17 & 14.1 & 13.4 \\
\hline Railroad Rolling Stock & 0.23 & 30.2 & 22.4 \\
\hline Ship and Boat Building & 0.51 & 11.3 & 10.8 \\
\hline Other Transportation Equipment & 0.16 & 25.4 & 17.1 \\
\hline Household and Institutional Furniture and Kitchen Cabinets & 0.87 & 18.5 & 7.1 \\
\hline Office and Other Furniture & 0.62 & 13.4 & 8.7 \\
\hline Medical Equipment and Supplies & 1.18 & 6.7 & 5.4 \\
\hline Other Miscellaneous Manufacturing & 1.36 & 11.3 & 5.8 \\
\hline Newspaper Publishers & 1.47 & 6.0 & 6.7 \\
\hline Periodical, Book, and Other Publishers & 1.99 & 9.0 & 7.3 \\
\hline
\end{tabular}


Figure 1

Growth Rates of Industrial Production

(Percentage points at an annual rate)

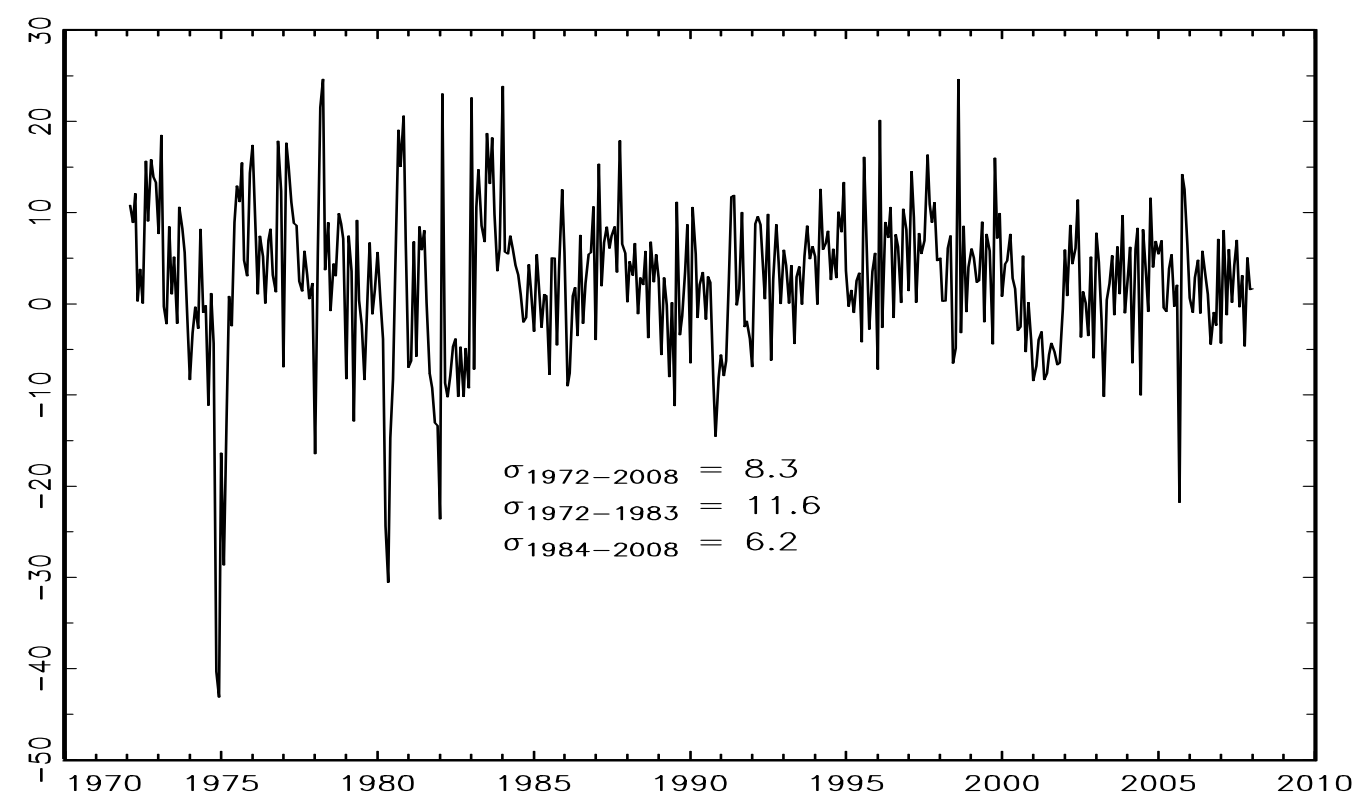

A. Monthly Data

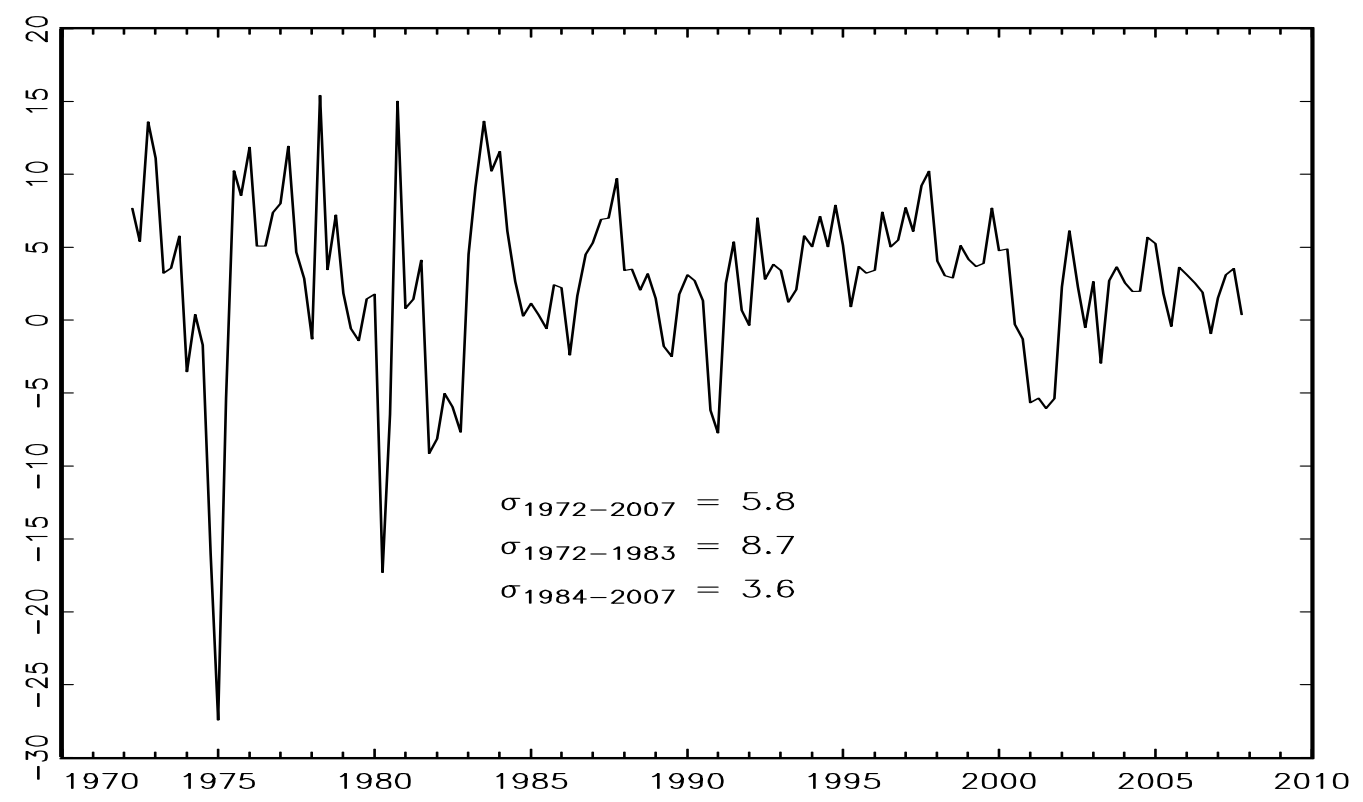

B. Quarterly Data 
Figure 2

Standard Deviation of Sectoral IP Growth Rates

(Percentage points at an annual rate)

(i) $1972-1983$

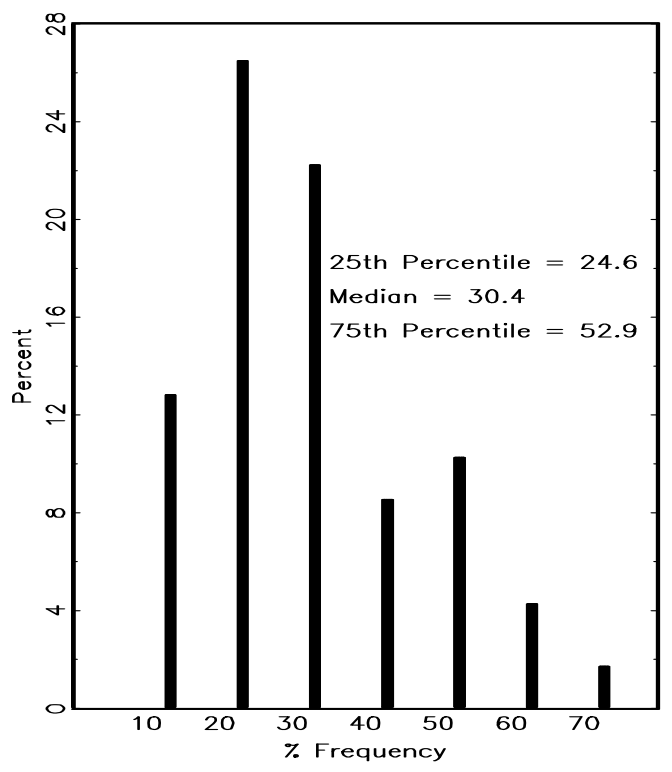

(ii) $1984-2008$

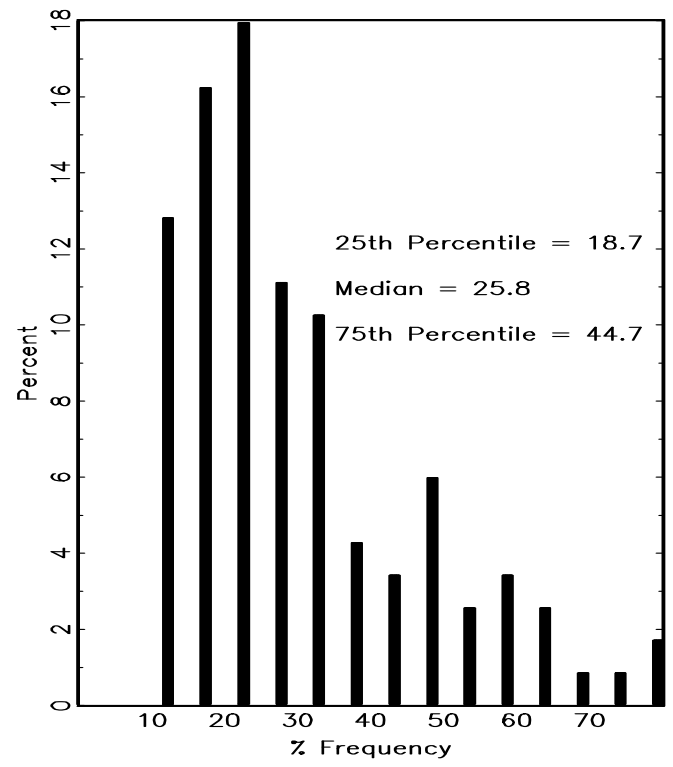

A. Monthly Growth Rates

(i) $1972-1983$

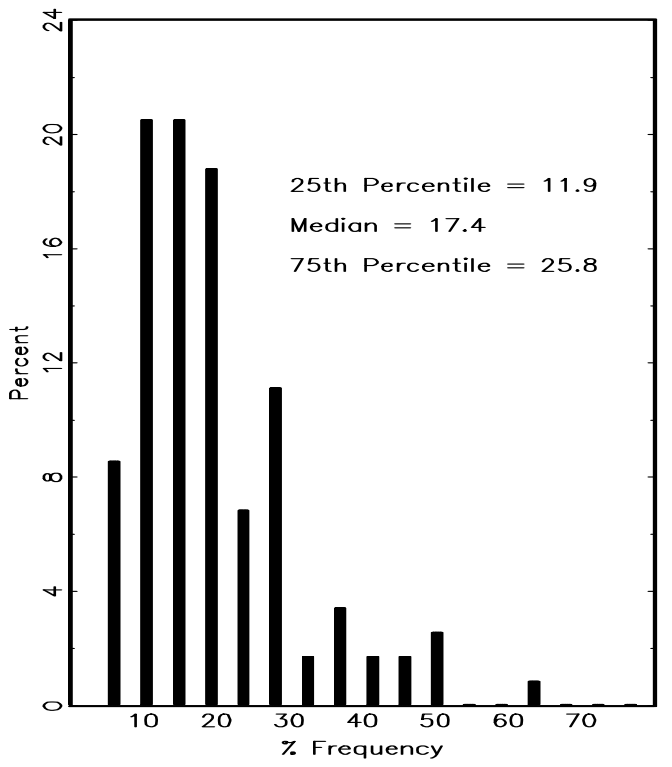

(ii) $1984-2007$

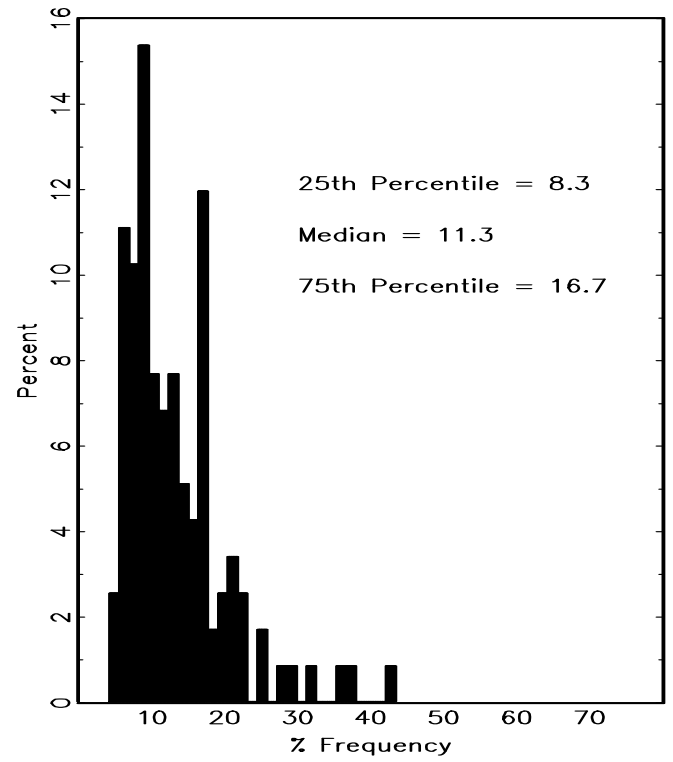

B. Quarterly Growth Rates 
Figure 3

Factor Decomposition of Industrial Production

(Percentage points at an annual rate)

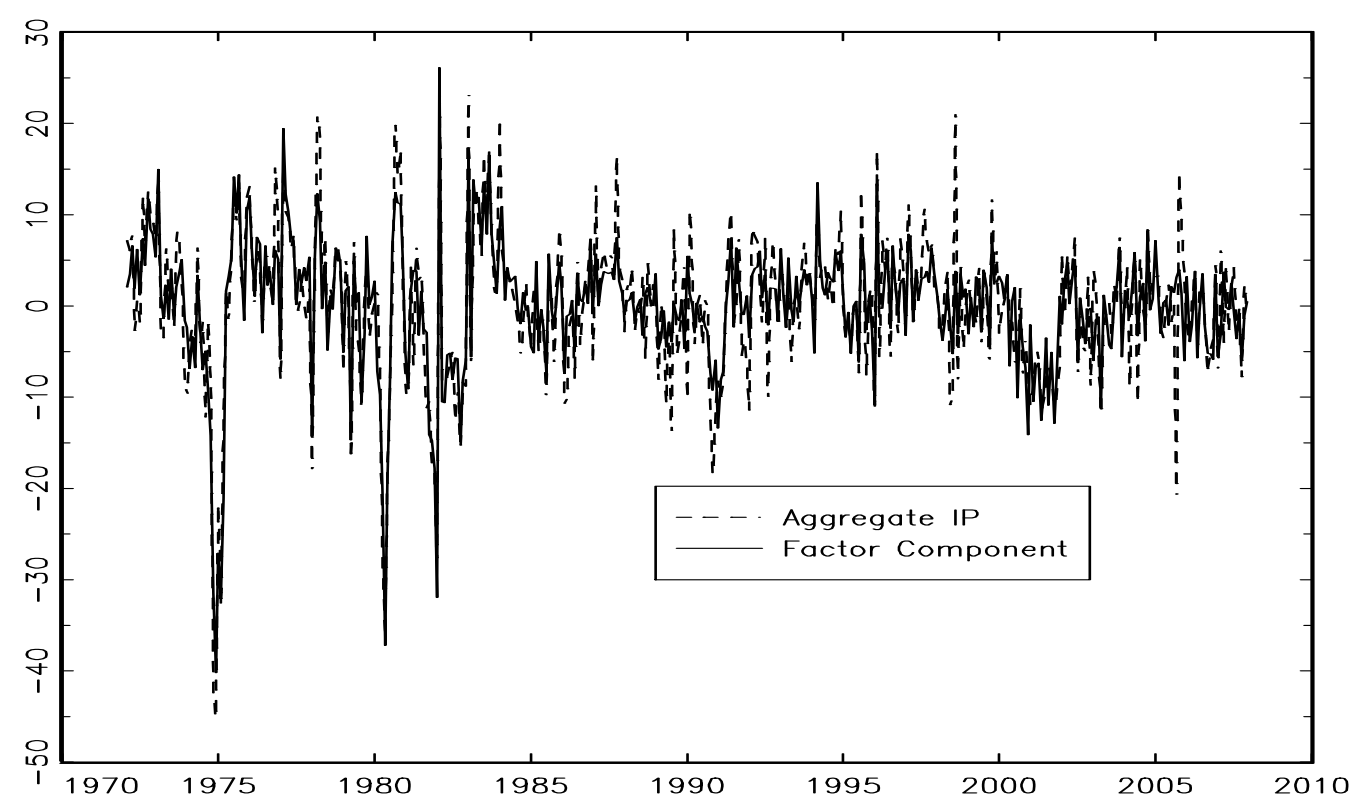

A. Monthly Data

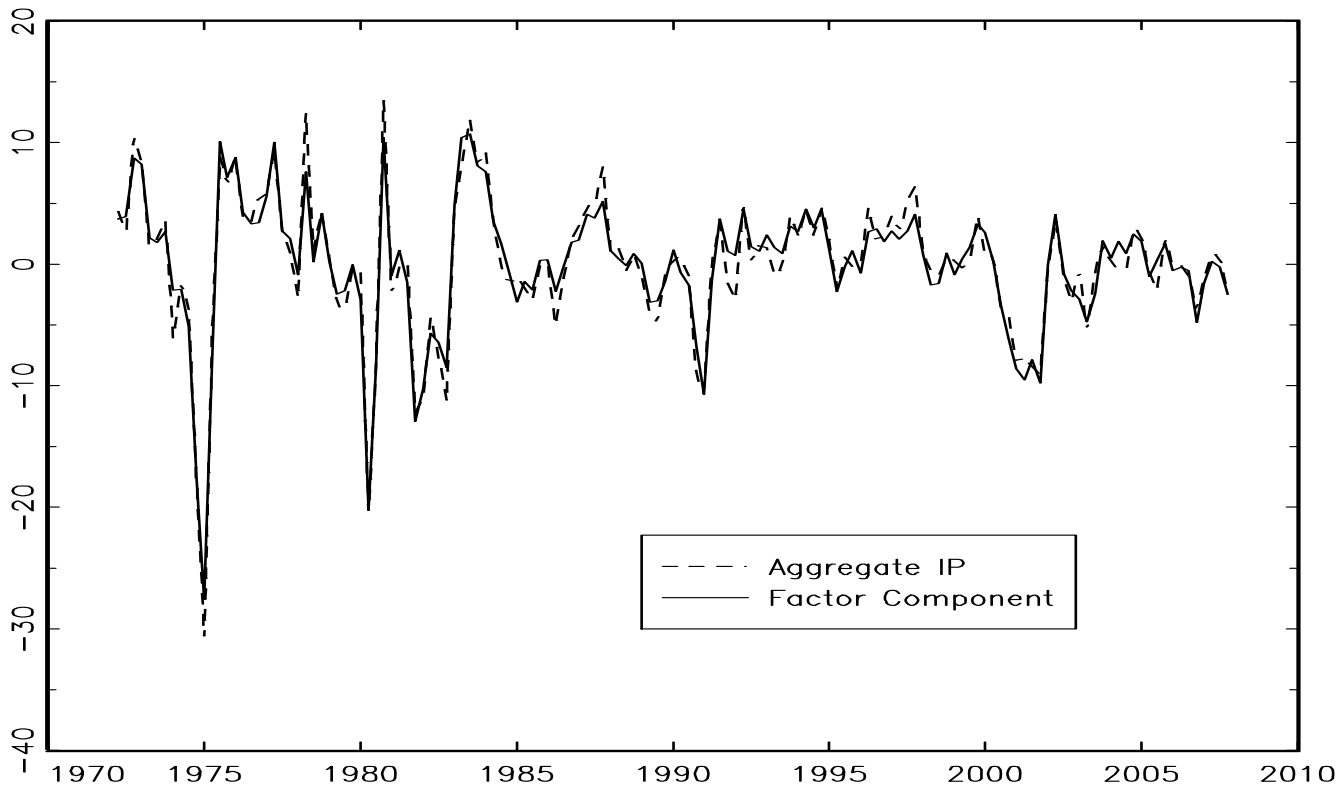

B. Quarterly Data 
Figure 4

Distribution of $R_{i}^{2}(F)$ of Sectoral Growth Rates

(i) $1972-1983$

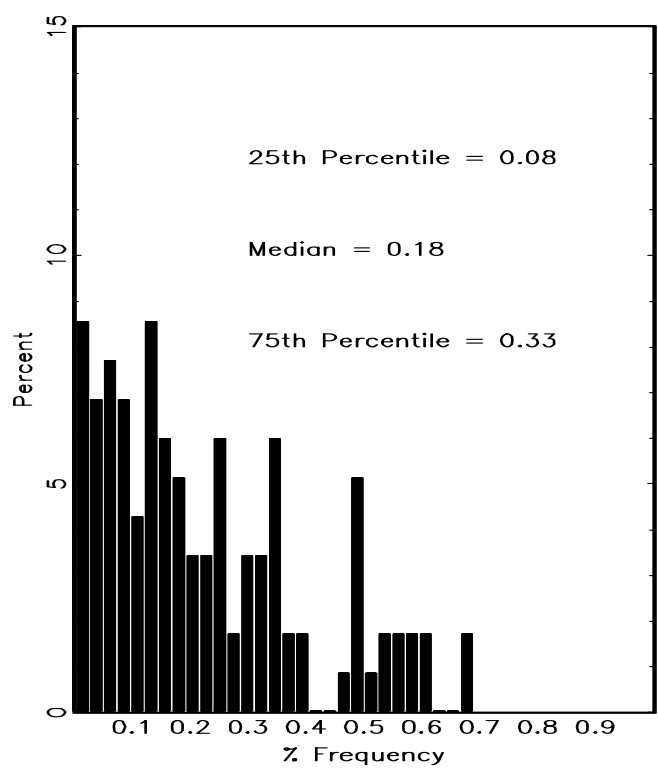

(ii) $1984-2007$

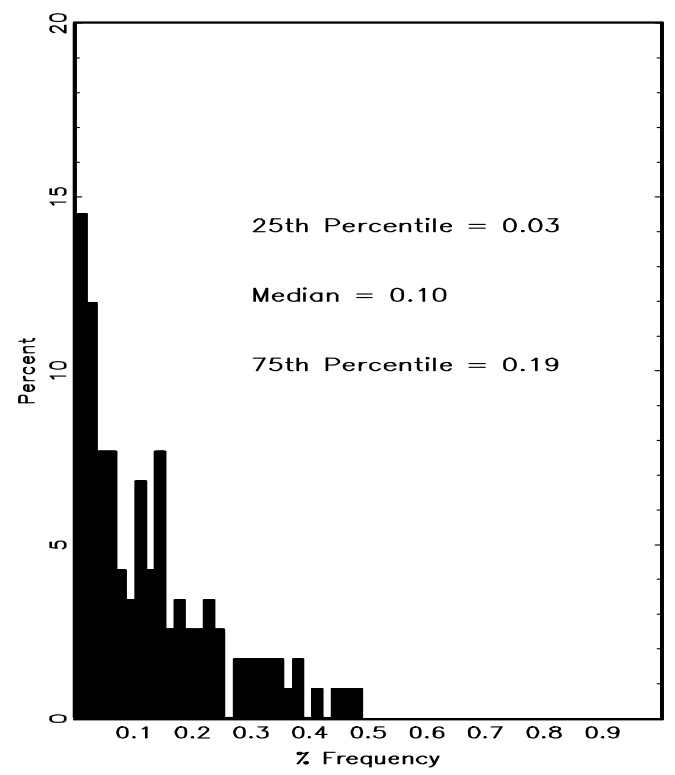

A. Monthly Growth Rates

(i) $1972-1983$

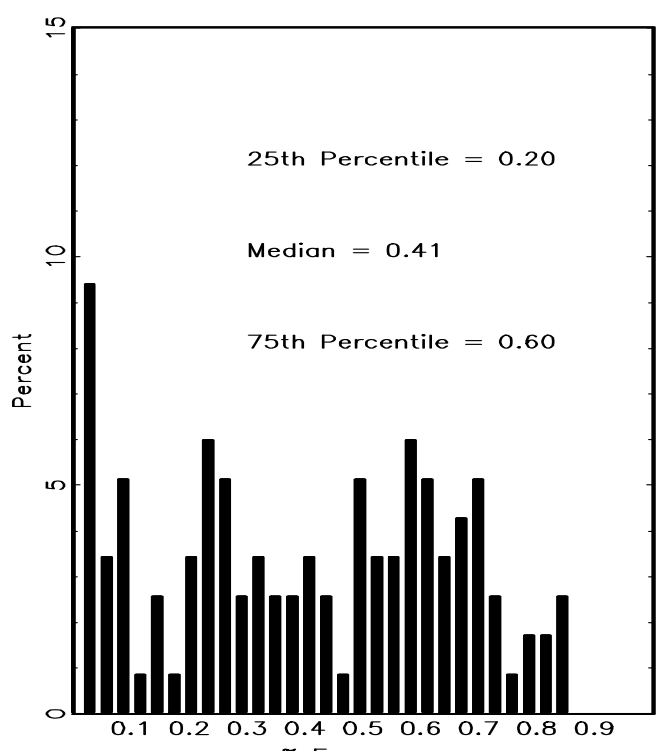

7. Frequency (ii) $1984-2007$

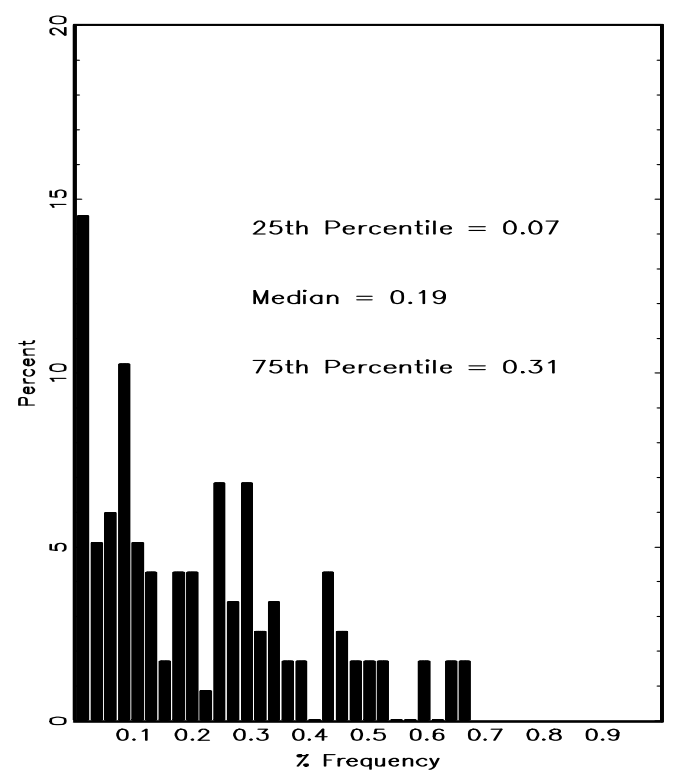

B. Quarterly Growth Rates 
Table 1

Average Pairwise Correlation of Sectoral IP Growth Rates

\begin{tabular}{cccccc}
\hline \hline \multicolumn{3}{c}{ Monthly Growth Rates } & \multicolumn{3}{c}{ Quarterly Growth Rates } \\
\hline $1972-2007$ & $1972-1983$ & $1984-2007$ & $1972-2007$ & $1972-1983$ & $1984-2007$ \\
0.08 & 0.13 & 0.05 & 0.19 & 0.27 & 0.11 \\
\hline
\end{tabular}

Table 2

Standard Deviation of IP Growth Rates

(Percentage points at annual rate)

\begin{tabular}{|c|c|c|c|c|c|c|}
\hline \multirow{3}{*}{$\begin{array}{l}\text { Share Weights Used to } \\
\text { Aggregate Sectoral IP }\end{array}$} & \multicolumn{3}{|c|}{ Monthly Growth Rates } & \multicolumn{3}{|c|}{ Quarterly Growth Rates } \\
\hline & $1972-$ & $1972-$ & $1984-$ & $1972-$ & $1972-$ & $1984-$ \\
\hline & 2007 & 1983 & 2007 & 2007 & 1983 & 2007 \\
\hline \multicolumn{7}{|c|}{ a. Full Covariance Matrix of Sectoral Growth Rates } \\
\hline Time Varying $\left(w_{i t}\right)$ & 8.3 & 11.6 & 6.2 & 5.8 & 8.7 & 3.6 \\
\hline Constant $\left(\mu_{w}\right)$ & 8.4 & 11.7 & 6.2 & 5.8 & 8.9 & 3.6 \\
\hline Equal $(1 / N)$ & 10.4 & 14.4 & 7.6 & 6.9 & 10.5 & 4.2 \\
\hline \multicolumn{7}{|c|}{ b. Diagonal Covariance Matrix of Sectoral Growth Rates } \\
\hline Time Varying $\left(w_{i t}\right)$ & 4.3 & 4.9 & 4.1 & 1.9 & 2.6 & 1.6 \\
\hline Constant $\left(\mu_{w}\right)$ & 4.2 & 4.6 & 4.0 & 1.9 & 2.4 & 1.5 \\
\hline Equal $(1 / N)$ & 4.6 & 5.6 & 4.0 & 1.8 & 2.5 & 1.4 \\
\hline
\end{tabular}

Table 3

Decomposition of Variance from Statistical 2-Factor Model

\begin{tabular}{ccccc}
\hline \hline & \multicolumn{2}{c}{ Monthly Growth Rates } & \multicolumn{2}{c}{ Quarterly Growth Rates } \\
& $1972-1983$ & $1984-2007$ & $1972-1983$ & $1984-2007$ \\
\hline $\begin{array}{c}\text { Std. Deviation of IP Growth Rates } \\
\quad \text { Implied by Factor Model } \\
\text { (with Constant Share Weights) } \\
R^{2}(F)\end{array}$ & 11.7 & 6.2 & 8.9 & 3.6 \\
\hline
\end{tabular}


Table 4

Fraction of Variability in Sectoral Growth Rates Explained by Common Factors (Quarterly Data)

\begin{tabular}{ll}
\hline \hline & $1972-1983$ \\
Sector & $R_{i}^{2}(F)$ \\
\hline Other Fabricated Metal Products & 0.86 \\
Fabricated Metals: Forging and Stamping & 0.85 \\
Machine Shops: Turned Products and Screws & 0.83 \\
Commercial and Service Industry Machinery/Other General Purpose Machinery & 0.83 \\
Foundries & 0.80 \\
Other Electrical Equipment & 0.79 \\
Metal Working Machinery & 0.78 \\
Fabricated Metals: Cutlery and Handtools & 0.76 \\
Electrical Equipment & 0.73 \\
Architectural and Structural Metal Products & 0.72 \\
\hline & \\
Sector & $R_{i}^{2}(F)$ \\
\hline Coating, Engraving, Heat Treating, and Allied Activities & 0.68 \\
Plastic Products & 0.67 \\
Commercial and Service Industry Machinery/Other General Purpose Machinery & 0.65 \\
Fabricated Metals: Forging and Stamping & 0.65 \\
Household and Institutional Furniture and Kitchen Cabinets & 0.59 \\
Veneer, Plywood, and Engineered Wood Products & 0.59 \\
Metal Working Machinery & 0.52 \\
Foundries & 0.52 \\
Millwork & 0.51 \\
\hline
\end{tabular}


Table 5

Information Content of IP Contained in Individual Sectors

\begin{tabular}{|c|c|c|}
\hline $\begin{array}{l}\text { Selected Sectors Ranked } \\
\text { by } R_{i}^{2}(F)\end{array}$ & $\begin{array}{l}\text { Fraction of IP Explained } \\
\text { by Selected Sectors: } 1972-1983\end{array}$ & $\begin{array}{l}\text { Fraction of IP Explained } \\
\text { by Selected Sectors: } 1972-1983\end{array}$ \\
\hline Top 5 Sectors & 85.0 & 75.4 \\
\hline Top 10 Sectors & 90.3 & 80.4 \\
\hline Top 20 Sectors & 97.9 & 86.4 \\
\hline Top 30 Sectors & 98.8 & 90.3 \\
\hline
\end{tabular}

Table 6 Sectoral Correlations and Volatility of IP Growth Rates

Quarterly U.S. Data and Values Implied by Model with Uncorrelated Sector-Specific Shocks

\begin{tabular}{|c|c|c|c|c|c|c|c|c|}
\hline & \multicolumn{4}{|c|}{ NAICS (1998 IO Matrix) } & \multicolumn{4}{|c|}{ SIC (1977 IO Matrix) } \\
\hline & \multicolumn{2}{|c|}{$\underline{1972-1983}$} & \multicolumn{2}{|c|}{$\underline{1984-2007}$} & \multicolumn{2}{|c|}{$\underline{1967-1983}$} & \multicolumn{2}{|c|}{$\underline{1984-2002}$} \\
\hline & Data & Model & Data & Model & Data & Model & Data & Model \\
\hline Average Pairwise & & & & & & & & \\
\hline $\begin{array}{l}\text { Correlation of Sectoral } \\
\text { Growth Rates }\end{array}$ & 0.27 & 0.04 & 0.11 & 0.03 & 0.23 & 0.05 & 0.12 & 0.04 \\
\hline $\begin{array}{l}\text { Standard Deviation of } \\
\text { IP Growth Rate }\end{array}$ & 8.9 & 3.7 & 3.6 & 2.2 & 8.5 & 4.0 & 3.9 & 2.4 \\
\hline
\end{tabular}




\section{Table 7}

Largest Eigenvalues of Sample Correlation Matrix

IO Model with Uncorrelated Sector-Specific Shocks

\begin{tabular}{|c|c|c|c|c|c|c|c|c|}
\hline \multirow[b]{4}{*}{ Eigenvalue Rank } & \multicolumn{8}{|c|}{ a. NAICS (1998 IO Matrix) } \\
\hline & \multicolumn{4}{|c|}{$1972-1983$} & \multicolumn{4}{|c|}{ 1984-2007 } \\
\hline & \multicolumn{5}{|c|}{ Model \%-tiles } & \multicolumn{3}{|c|}{ Model \%-tiles } \\
\hline & Data & 1 & 50 & 99 & Data & 1 & 50 & 99 \\
\hline 1 & 39.4 & 6.6 & 8.0 & 10.1 & 18.5 & 4.7 & 5.5 & 6.7 \\
\hline 2 & 11.0 & 5.8 & 6.4 & 7.3 & 6.7 & 4.1 & 4.5 & 5.0 \\
\hline 3 & 5.9 & 5.3 & 5.8 & 6.3 & 5.1 & 3.8 & 4.1 & 4.5 \\
\hline 4 & 4.8 & 5.0 & 5.4 & 5.8 & 4.4 & 3.6 & 3.8 & 4.1 \\
\hline 5 & 4.6 & 4.7 & 5.0 & 5.4 & 4.1 & 3.5 & 3.7 & 3.9 \\
\hline 6 & 4.1 & 4.5 & 4.8 & 5.1 & 3.6 & 3.3 & 3.5 & 3.7 \\
\hline \multirow[t]{4}{*}{7} & 3.5 & 4.2 & 4.5 & 4.8 & 3.4 & 3.2 & 3.4 & 3.5 \\
\hline & \multicolumn{8}{|c|}{ b. SIC (1977 IO Matrix) } \\
\hline & \multicolumn{4}{|c|}{$1967-1983$} & \multicolumn{4}{|c|}{ 1984-2002 } \\
\hline & \multicolumn{5}{|c|}{ Model \%-tiles } & \multicolumn{3}{|c|}{ Model \%-tiles } \\
\hline Eigenvalue Rank & Data & 1 & 50 & 99 & Data & 1 & 50 & 99 \\
\hline 1 & 30.8 & 5.9 & 7.4 & 9.2 & 16.9 & 5.2 & 6.2 & 7.7 \\
\hline 2 & 9.1 & 4.6 & 5.1 & 5.8 & 6.0 & 4.3 & 4.8 & 5.5 \\
\hline 3 & 4.6 & 4.3 & 4.6 & 5.1 & 4.7 & 4.0 & 4.4 & 4.8 \\
\hline 4 & 4.2 & 4.0 & 4.3 & 4.7 & 4.3 & 3.8 & 4.1 & 4.4 \\
\hline 5 & 3.6 & 3.8 & 4.1 & 4.4 & 4.0 & 3.6 & 3.9 & 4.1 \\
\hline 6 & 3.4 & 3.6 & 3.8 & 4.1 & 3.9 & 3.5 & 3.7 & 3.9 \\
\hline 7 & 3.1 & 3.4 & 3.7 & 3.9 & 3.6 & 3.3 & 3.5 & 3.7 \\
\hline
\end{tabular}


Table 8

Sectoral Correlations and Volatility of IP Growth Rates

Quarterly U.S. Data and Values Implied by 2-factor Model for Sector-Specific Shocks

\begin{tabular}{|c|c|c|c|c|c|c|c|c|}
\hline & \multicolumn{4}{|c|}{ "NAICS (1998 IO Matrix) } & \multicolumn{4}{|c|}{ SIC (1977y IO Matrix) } \\
\hline & \multicolumn{2}{|c|}{$\underline{1972-1983}$} & \multicolumn{2}{|c|}{$\underline{1984-2007}$} & \multicolumn{2}{|c|}{$\underline{1967-1983}$} & \multicolumn{2}{|c|}{$\underline{1984-2002}$} \\
\hline & Data & Model & Data & Model & Data & Model & Data & Model \\
\hline Average Pairwise & & & & & & & & \\
\hline $\begin{array}{l}\text { Correlation of Sectoral } \\
\text { Growth Rates }\end{array}$ & 0.27 & 0.27 & 0.11 & 0.11 & 0.23 & 0.23 & 0.12 & 0.12 \\
\hline $\begin{array}{l}\text { Standard Deviation of } \\
\text { IP Growth Rate }\end{array}$ & 8.9 & 9.1 & 3.6 & 3.7 & 8.5 & 8.8 & 3.9 & 4.2 \\
\hline
\end{tabular}


Table 9

Largest Eigenvalues of Sample Correlation Matrix

IO Model with 2 Factors for Sector-Specific Shocks

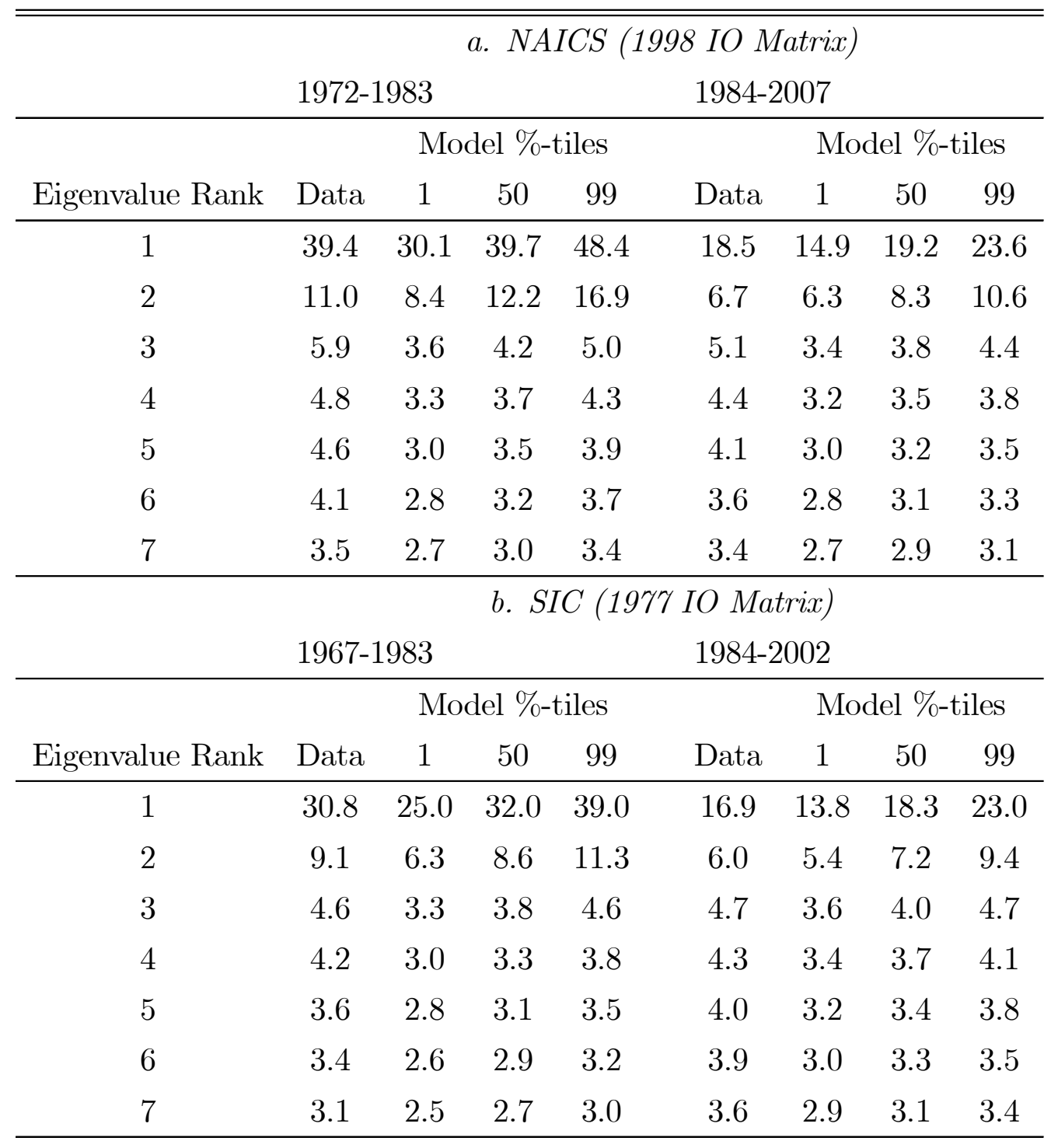


Table 10

Decomposition of Variance from Statistical and Structural 2-Factor Models

\begin{tabular}{lcccc}
\hline \hline & \multicolumn{2}{c}{ NAICS Definitions } & \multicolumn{2}{c}{ SIC Definitions } \\
& $1972-1983$ & $1984-2007$ & $1967-1983$ & $1984-2002$ \\
\hline Std. Deviation of IP Growth Rates & 8.9 & 3.6 & 8.5 & 3.9 \\
& & & & \\
$R^{2}(F)$ - Statistical Model & 0.89 & 0.87 & 0.85 & 0.94 \\
$R^{2}(S)$ - Structural Model & 0.88 & 0.69 & 0.83 & 0.72 \\
\hline
\end{tabular}


Table 11

Fraction of Aggregate IP Explained by Sector-Specific Shocks

2-Factor Model, 10 Largest Values

\begin{tabular}{lc}
\hline \hline \multicolumn{1}{c}{$a .1967-1983(S I C)$} & \\
Sector & Fraction \\
\hline Basic Steel and Mill Products & 0.064 \\
Coal Mining & 0.034 \\
Motor Vehicles, Trucks, and Buses & 0.008 \\
Utilities & 0.007 \\
Oil and Gas Extraction & 0.005 \\
Copper Ores & 0.004 \\
Iron and Other Ores & 0.003 \\
Petroleum Refining and Miscellaneous & 0.003 \\
Motor Vehicle Parts & 0.003 \\
Electronic Components & 0.002 \\
\hline & \\
\hline & 1984-2007 (NAICS) \\
Iron and Steel Products & \\
Electric Power Generation and Distribution & 0.042 \\
Semiconductors and Other Electronic Components & 0.036 \\
Oil and Gas Extraction & 0.017 \\
Automobiles and Light Duty Motor Vehicles & 0.017 \\
Organic Chemicals & 0.017 \\
Natural Gaspace Products and Parts & 0.015 \\
\hline & 0.013 \\
\hline & 0.012 \\
Support Activity for Mining & 0.011 \\
\hline
\end{tabular}


Table 12

Sectoral Correlations and Fraction of IP Variance

Explained by Aggregate Shocks

\begin{tabular}{|c|c|c|c|c|}
\hline Capital Depreciation Rate & \multicolumn{2}{|c|}{$\delta=0.025$} & \multicolumn{2}{|c|}{$\delta=1$} \\
\hline \multicolumn{5}{|c|}{ a. NAICS (1998 IO Matrix) } \\
\hline & $1972-1983$ & 1984-2007 & $1972-1983$ & 1984-2007 \\
\hline \multicolumn{5}{|l|}{ Fraction of Aggregate IP Variance } \\
\hline Explained by Aggregate Shocks, $R^{2}(S)$ & 0.88 & 0.69 & 0.74 & 0.30 \\
\hline \multicolumn{5}{|l|}{ Average Pairwise Correlation of } \\
\hline Sectoral IP Growth Rates (0 factors) & 0.04 & 0.03 & 0.09 & 0.07 \\
\hline \multicolumn{5}{|c|}{ b. SIC (1977 IO Matrix) } \\
\hline & $1972-1983$ & 1984-2007 & $1972-1983$ & 1984-2007 \\
\hline \multicolumn{5}{|l|}{ Fraction of Aggregate IP Variance } \\
\hline Explained by Aggregate Shocks, $R^{2}(S)$ & 0.83 & 0.72 & 0.61 & 0.39 \\
\hline \multicolumn{5}{|l|}{ Average Pairwise Correlation of } \\
\hline Sectoral IP Growth Rates (0 factors) & 0.05 & 0.04 & 0.10 & 0.08 \\
\hline
\end{tabular}

Table 13

Sectoral Correlations and Fraction of IP Variance Explained

by Aggregate Shocks Across Levels of Disaggregation

\begin{tabular}{lcccc}
\hline \hline & \multicolumn{2}{c}{ 1972-1983 } & \multicolumn{2}{c}{ 1984-2007 } \\
a. Average Pairwise Correlation of Sectoral & Growth & Rates \\
\hline & Model & Data & Model & Data \\
2-Digit Level, 26 Sectors & 0.12 & 0.43 & 0.11 & 0.28 \\
3-Digit Level, 88 Sectors & 0.05 & 0.31 & 0.04 & 0.15 \\
4-Digit Level, 117 Sectors & 0.04 & 0.27 & 0.03 & 0.11 \\
\hline b. Fraction of IP Variance Explained by & Aggregate Shocks \\
\hline 2-Digit Level, 26 Sectors & 0.87 & \multicolumn{4}{c}{0.70} \\
3-Digit Level, 88 Sectors & 0.88 & & 0.70 \\
4-Digit Level, 117 Sectors & 0.88 & & 0.69 \\
\hline
\end{tabular}

